\title{
Application of Carbonized Starches as Carbon Electrode Active Material Compared to Graphene Nanoplatelets-Based Anode in a Lithium-Ion Cell
}

\author{
Marita Pigłowska' $\cdot$ Beata Kurc $^{2} \cdot$ Łukasz Rymaniak $^{3}$
}

Received: 5 November 2020 / Accepted: 30 April 2021 / Published online: 15 May 2021

(c) The Author(s) 2021

\begin{abstract}
The main aim of this research is the examination of the physicochemical properties and their impact on the electrochemical activity of carbon materials obtained from the starch of different botanical origin (SCs). The obtained materials are compared to graphene nanoplatelets (GNPs) of different particle sizes (5 and $25 \mu \mathrm{m})$ applied as an anode active material for high-performance lithium-ion cells. SCs were obtained via thermal carbonization and this process enables an obtainment of better sorption properties compared to GNPs. The excellent electrochemical properties are mainly attributed to the good $\mathrm{D}_{\mathrm{Li}+}\left(3.03 \times 10^{-13}-7.64 \times 10^{-11} \mathrm{~cm}^{2} \mathrm{~s}^{-1}\right.$ for SCs and $7.60 \times 10^{-13}-5.42 \times 10^{-12} \mathrm{~cm}^{2} \mathrm{~s}^{-1}$ for GNPs) and relatively small resistances (EIS). However, the primary focus is on the specific capacity and cyclability. The capacity retentions of CSC cycled at $1 \mathrm{~mA} \mathrm{~g}^{-1}, 10 \mathrm{~mA} \mathrm{~g}^{-1}, 50 \mathrm{~mA} \mathrm{~g}^{-1}, 1 \mathrm{~mA} \mathrm{~g}^{-1}$ for 50 cycles are $98 \%, 99 \%, 96 \%, 94 \%$ with specific capacities equal to 820 , $800,790,1000 \mathrm{mAh} \mathrm{g}^{-1}$, respectively. The 5GNPs and 25GNPs may present a much smaller reversible capacity of 650 , $600 \mathrm{mAh} \mathrm{g}^{-1}$ at $10 \mathrm{~mA} \mathrm{~g}^{-1}$. The thermal modification process of starches is simple, safe and widely applied, providing new paths for rational engineering of anode materials for LIBs. Moreover, the applied materials are easily available worldwide and are promising in the well-known Green Chemistry aspect making the cells more biodegradable.
\end{abstract}

Beata Kurc

beata.kurc@put.poznan.pl

1 Faculty of Chemical Technology, Poznań University of Technology, Poznan, Poland

2 Institute of Chemistry and Electrochemistry, Faculty of Chemical Technology, Poznan University of Technology, Berdychowo 4, 60965 Poznan, Poland

3 Institute of Combustion Engines and Powertrains, Faculty of Civil and Transport Engineering, Poznan University of Technology, Piotrowo 3, 60965 Poznan, Poland 


\section{Graphic Abstract}

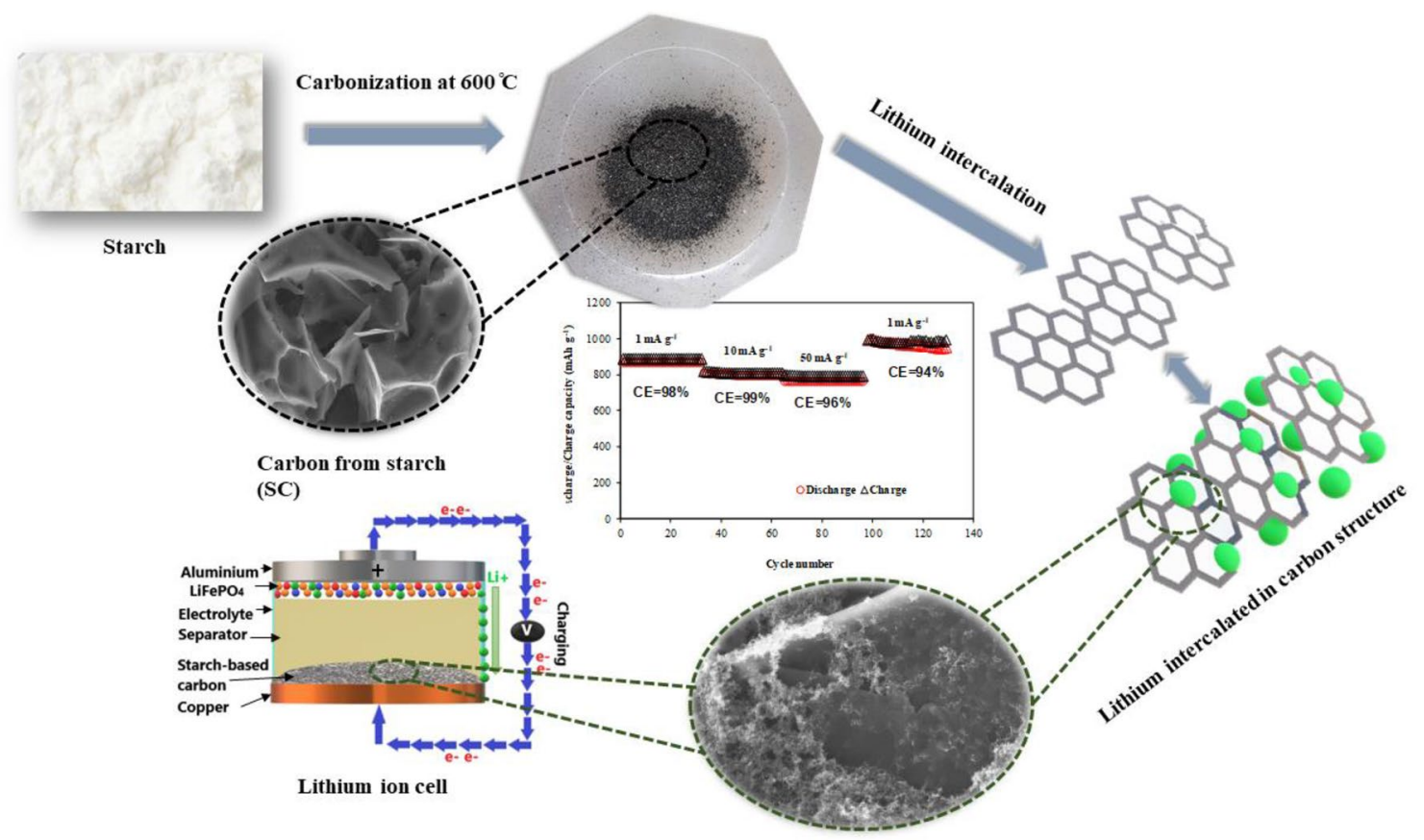

Keywords Botanical origin · Carbon materials · Capacity $\cdot$ Resistances $\cdot$ LIBs

\section{Statement of Novelty}

The work is a scientific novelty, because the obtained starch material has a similar structure to that of the graphene nanoplatelets that have recently been considered as anode active material for LiBs. The use of graphene materials in cells has its disadvantages such as large drops in specific capacity, electrochemical capacitor windows or instability during operation. The carbonized starches proposed in this paper do not exhibit such features. Thus far, current literature has not provided a comparison of the electrochemical behavior of four starches of different botanical origin. Starch is an easily available material, complies with the green chemistry policy and is easily processed as a carbonized carbon material. The obtained material increases the biodegradability of the cell.

\section{Introduction}

Lithium-ion batteries are lightweight and have a higher energy density than others, for example up to $50 \%$ compared to lead-acid batteries. This makes them a popular source of power supply in consumer electronics and electric cars. It is expected, that for a long time no other type of battery will compete them. Regardless of the type, each battery consists of four basic components: an anode, a cathode, a separator and electrolyte. The electrodes are made of various materials.

A widespread achievement in the technology industry, including electrochemistry, is the prevalence of machiningbased different allotropic varieties of coal. Organic electrodes require large amounts of conductive carbon (over $30 \%$ by weight) to maintain proper conductivity, which can significantly reduce the energy density of the entire cell [1].

Usually, graphite is used as an active material in Li-ion cell anodes because of its high stability, while its maximum capacity is limited to $372 \mathrm{mAh} \mathrm{g}^{-1}$ due to $\mathrm{LiC}_{6}$ binding in accordance with the reaction: $\mathrm{C}_{6}+\mathrm{Li}^{+}+\mathrm{e}-\leftrightarrow \mathrm{LiC}_{6}$. There also exists the increased intercalation of solvated lithium ions, therefore graphite ceases to fulfill its role as an active material in the lithium-ion cells $[1,2]$. Dry mass doping is used to create the electrode paste to increase the material stability. The greatest development of the carbon-based materials in lithium-ion cells concerns their use as an active material anode or cathode conductive diluent [3].

As the anode carbon materials used in various industries we may distinguish HOPG (highly oriented pyrolysis graphite), natural graphite, artificial (synthetic) graphite, hard carbons, soft carbons, carbon nanotubes, low-temperature mesophase materials and MCMB carbons [2, 3]. For example, hard coals exhibit the largest capacity possible. Excellent 
performance, flatness of discharge, high operating voltage, significant low temperature performance and electrical conductivity are observed for synthetic graphite.

Mesophase carbon fibers (MCFs) (Fig. 1) have a radial crystal orientation that is capable of seamlessly building in lithium ions on either side of the material surface walls. The sidewall is covered with a thin, porous, graphene layer that protects the fiber from changing shape during intercalation and deintercalation of lithium during swelling and volume reduction. The phenomenon of these batteries is the use (in addition to MCF or BMCF) of new electrolytes containing $\mathrm{LiBF}_{4}$ particles dissolved in $\mathrm{EC} / \mathrm{MEC} / \gamma-\mathrm{BL}$ and an aluminum tank made of laminated plastic.

The hard carbons are formed when heating thermosetting resins (such as sugars, proteins, cellulose) in a vacuum or inert gas atmosphere. As a result of a thermal decomposition, water (syneresis) and gases are released obtaining the appropriate form of carbon whose particles are naturally joined creating a complex structure that is unable to transform into the form of graphite. The results of this form of carbon are: high hardness, indeterminate crystal structure, randomly distributed graphite structure as well as cavities and voids. The significant advantage is the inability of these forms to break down PC (propylene carbonate). However, $\mathrm{PC}$ has the ability to energetically disintegrate, when in contact with lithium graphite. These are two remarkable advantages of the use of hard carbons compared to graphite [2].

Carbon nanotubes (CNTs) in variously modified forms are extremely popular. Their wide application originates in the strong carbon-carbon covalent bond, which enables high stability, closed topology, increased conductivity and excellent strength properties. Depending on the degree of graphitization, the single-walled SWCNT variant or the carbon nanotubes of higher capacity (multi-walled MWCNT) are used (compared to graphite). SWCNTs exhibit the reversible capacity of lithium $460 \mathrm{mAh} \mathrm{g}^{-1}$, while MWCNTs can reach $980 \mathrm{mAh} \mathrm{g}^{-1}$, which is much higher than the capacity of graphite $\left(372 \mathrm{mAh} \mathrm{g}^{-1}\right)$. CNFs (carbon nanofibers subjected to graphitization at $550-700{ }^{\circ} \mathrm{C}$ ) are also widely used. They show a high capacity in the range of $297-431 \mathrm{mAh} \mathrm{g}^{-1}$ and a satisfactory $60 \%$ coulombic efficiency of the first cycle. Extremely forward-looking applications as anode material in a Li-ion cell find graphene-based nanocomposites. Graphene nanoflakes used as the active material of the negative electrode reach half-cell capacities up to $700 \mathrm{mAh} \mathrm{g}^{-1}$ [1].

There are many reports in the literature regarding $\mathrm{Li}$-ion batteries that show the possibility of use of the construction of different carbonaceous materials such as activated carbons in a powder form [5, 6], carbon materials obtained from carbides [7, 8], woven carbon fiber [9, 10], carbon nanofibers [11, 12], carbon onions [13], carbon nanotubes [13-15], carbon nanospheres [16], etc. This statement is incorrect, particularly since the highly porous carbon electrodes have a lower mass than the adsorbed electrolyte contained in them [17].

Despite the great interest of the scientific world in synthetic polymers, increasing emphasis is put on the green aspects. Thus, biopolymers are a good substitute for them. Nevertheless, the energy demand and the complexity of the processes used to isolate these biopolymers still turn out to be a big challenge [18]. One of the methods of modifying these polymers is the enzymatic processes. Amylases are often used as environmentally friendly enzymes, especially in food technology [19]. The processing of biopolymers does not only concern applications in packaging, medicines, agriculture, electrochemistry or food and material technologies
Fig. 1 Carbon-based materials used in LIBs, electrochemical capacitors and hybrid systems based on literature [4]

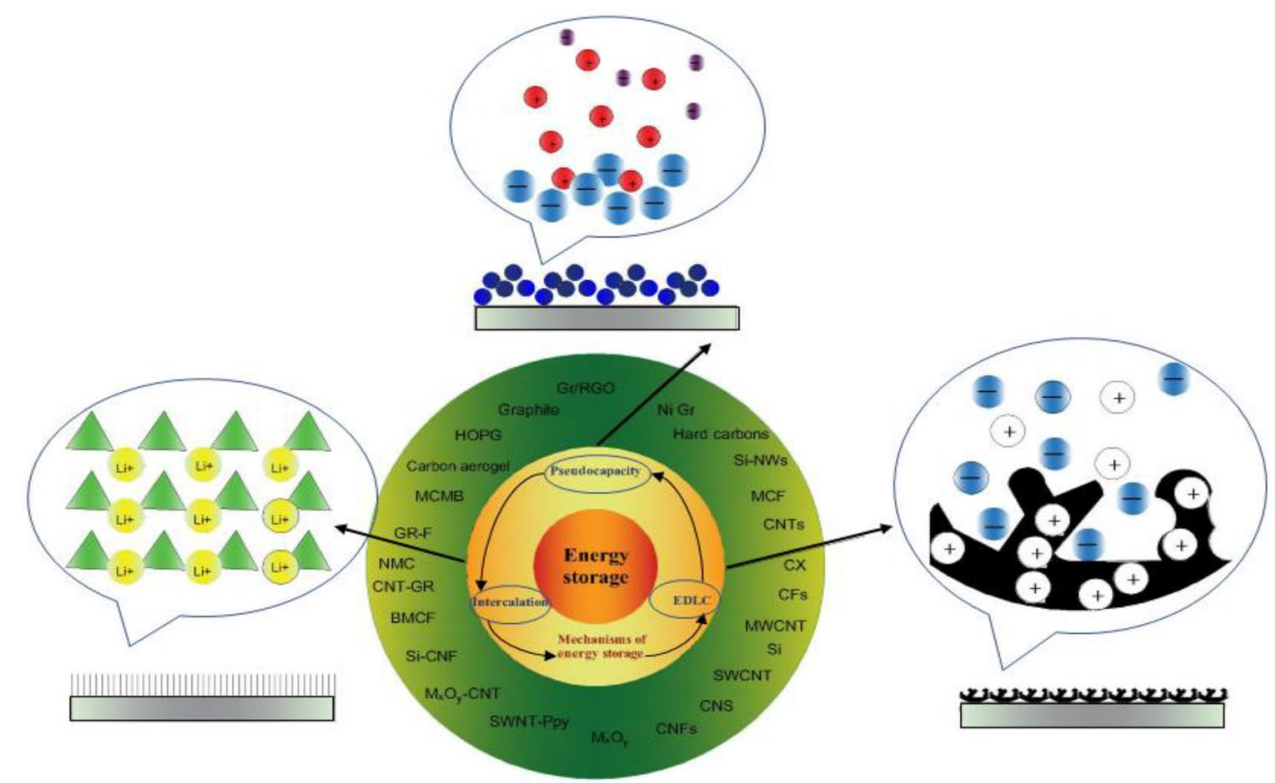


[20]. They are widely used in the production of renewable and environmentally friendly fuels. Thanks to this, the deepening coal deficit is counterbalanced and the environmental pollution is thus reduced [21].

The presented research addresses important issues concerning the development of safe lithium batteries. Careful observation of the phenomena and processes occurring during the oxidation and reduction of new electrode materials is the foundation of the work. A lot of physicochemical properties of new electrode materials was undertaken using the results of such analytical techniques as: infrared spectroscopy with the Fourier transformation (a technique used to obtain an infrared spectrum of solid body absorption or emission-FTIR), scanning electron microscopy (SEM) and gas adsorption analysis neutral (BET). The most important part, however, concerns the determination of the electrochemical properties of the tested compounds and linking them with the structural and morphological features of the analyzed materials.

The novelty of the work is certainly the comparison of the electrochemical properties of four starches of different botanical origin. Such an analysis of the physicochemical and electrochemical properties has not yet been described in the literature. The aim of the work is to prove that carbon materials obtained from a simple modification of biopolymers can achieve better electrochemical characteristics than graphene nanoplatelets used as electrode materials in lithium-ion cells.

\section{The Experimental Procedure}

\section{Materials}

Starches and graphene nanoplatelets were purchased from Sigma-Aldrich (USA). In the research rice, corn, potato and wheat starch, graphene nanoplatelets $(5 \mu \mathrm{m}$ particle size, surface area $120-150 \mathrm{~m}^{2} \mathrm{~g}^{-1}$ ), and graphene nanoplatelets
(25 $\mu \mathrm{m}$ particle size, surface area $50-80 \mathrm{~m}^{2} \mathrm{~g}^{-1}$ ) were applied. Graphene nanoplatelets of $25 \mu \mathrm{m}$ particle size will be replaced with 25 GNPs and of $5 \mu \mathrm{m}$ particle size with 5 GNPs in the following research. In the world, biomass can be obtained from various agricultural sources such as animals, plants, invasive weeds, food waste etc. [22].

\section{Preparation of the Carbonized Starch}

Starches were prepared via carbonization in the nitrogen atmosphere (inert gas) in a tube furnace. The process was carried out for $6 \mathrm{~h}$, the heating rate was equal to $5^{\circ} \mathrm{C}$ $\min ^{-1}$. Additionally, the temperature was increased for 2 h. Finally, the carbonization process was carried out at a constant temperature of $600{ }^{\circ} \mathrm{C}$ for $4 \mathrm{~h}$. The nitrogen flow was $0.83 \mathrm{~L} \mathrm{~min}^{-1}$. The obtained starch-based carbon was graphene-like and exhibited a very low bulk density. All the carbonized starches (SCs) will be described briefly within the manuscript. Carbon obtained from rice, corn, wheat and potato-starch will be described briefly in the RSC, CSC, WSC and PSC research respectively. Unmodified starches will be marked RC, CS, WS and PS. The whole process of obtainment of the carbon material and the application has been described in Fig. 2.

\section{Physicochemical Properties}

The obtained materials were subjected to physicochemical characterization and detailed electrochemical analysis.

\section{Scanning Electron Microscopy (SEM)}

The scanning electron microscope is used to determine the morphological microstructure of granules. EVO40 (scanning microscope) tests (Zeiss, Jena, Germany) were carried out at Poznan University of Technology. The microscope accelerates electrons in the range from 0.2 to $30 \mathrm{kV}$ enabling satisfactory distribution of the scanned substance.
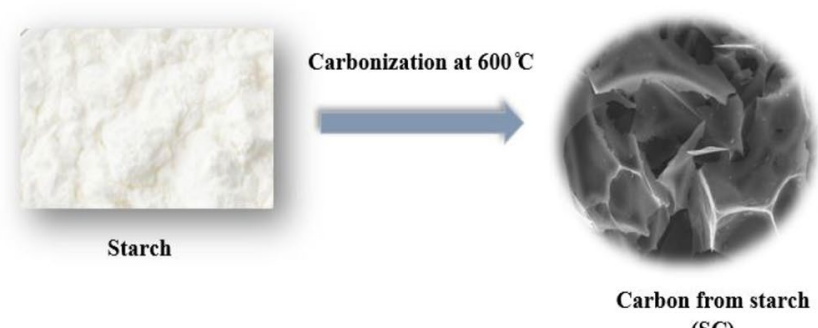

(SC)

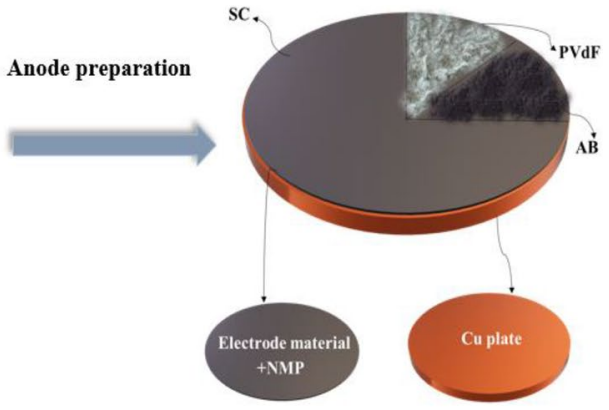

Anode for lithium-ion cell

Fig. 2 Preparation steps and application of carbonized material 


\section{Fourier Transform Infrared Spectroscopy (FTIR)}

Characteristic functional groups presented on the surface of the obtained hybrid materials were identified using the Fourier transform infrared spectroscopy (FTIR). The measurements were performed using a Vertex 70 spectrophotometer (Bruker, Germany). The samples were prepared by mixing with $\mathrm{KBr}$ and pressing into small tablets. The measurement was carried out in the wavenumber range 4000 to $400 \mathrm{~cm}^{-1}$.

\section{Brunauer-Emmett-Teller analysis (BET)}

For the BET analysis, ASAP 2020 by Micrometrics Instrument Corporation (USA) in low-temperature nitrogen adsorption was used. The samples were degassed at $120^{\circ} \mathrm{C}$ for four hours.

\section{Electrochemical Properties}

All electrodes were tested using cyclic voltammetry, electrochemical impendance spectroscopy and charge-discharge measurements.

\section{Cyclic Voltammetry (CV)}

The anode electrode pastes were created with polyvinylidene fluoride (PVdF), acetylene black (AB), N-Methyl-2-pyrrolidone (NMP) and carbonized starches SCs (or GNPs) as the active materials. All the measurements were performed for the scan rates of $1,2 \mathrm{mV} \mathrm{s}^{-1}$. A schematic diagram showing the structure of the cell has been shown in Fig. 3 .

The percentage amount of each dry component in the entire electrode paste has been presented in Table 1.

All dry components were dissolved in NMP and put onto the copper foil and dried under a vacuum atmosphere. In this research cell in Fig. 3 was used to investigate the

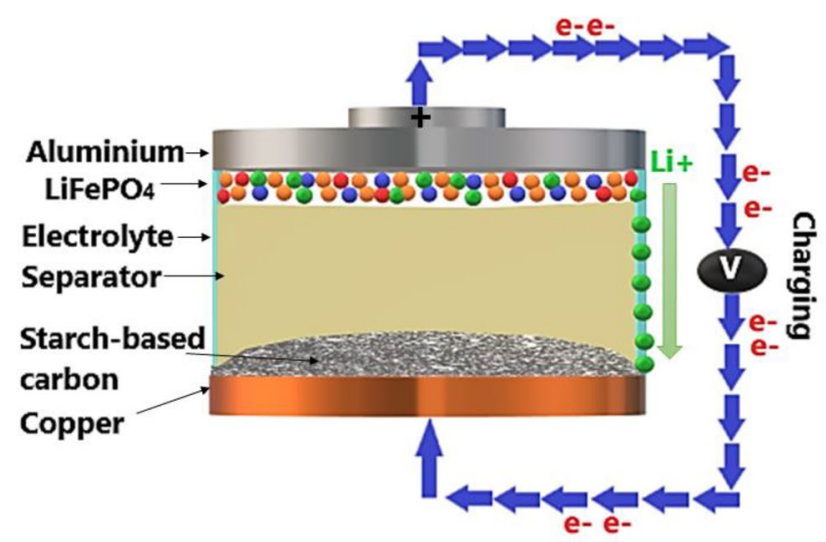

Fig. 3 Schematics of the Li-ion cell with carbon obtained from starch (SC) as an active anode material
Table 1 Anode material preparation

\begin{tabular}{ll}
\hline Component & Content (wt\%) \\
\hline GNPs/SC & 80 \\
AB & 10 \\
PVdF & 10 \\
\hline
\end{tabular}

electrochemical properties of SCs (or GNPs) as the proposed anode active material.

\section{Electrochemical Impedance Spectroscopy (EIS)}

The cell impedance was carried out using the GTM750 Potentiostat/Galvanostat/ZRA apparatus (Gamry Instruments, USA). The analysis was carried out in the frequency range of $100 \mathrm{kHz}$ to $10 \mathrm{MHz}$ and an alternating voltage amplitude of $10 \mathrm{mV}$. As a result of the measurement, the impedance spectra were presented in the real $(\mathrm{R})$ and imaginary (-iX) impedances. The unit of both impedances is $1 \Omega$.

\section{Charge-Discharge Test}

The electrochemical charging/discharging process was performed with the use of the G750 Potentiostat/Galvanostat Measurements System (Gamry, USA) at a room temperature.

The tested anodes were prepared on a copper foil (Hohsen, Japan) from a slurry of carbon (GNPs or SC), acetylene black $(\mathrm{AB})$ and $\mathrm{PVdF}$ in NMP. The ratio of components has been shown in Table 1 . After vacuum evaporation of the solvent (NMP) firstly at $60{ }^{\circ} \mathrm{C}(12 \mathrm{~h})$ and then $120^{\circ} \mathrm{C}(12 \mathrm{~h})$, the electrodes typically contained $3.5-4.2 \mathrm{mg}$ of carbon. A round-shaped lithium electrode (Aldrich, 0.75 $\mathrm{mm}$ thick) was used as the counter and reference electrode.

\section{Results and Discussion}

The obtained samples were characterized by physicochemical and electrochemical properties. An attempt was made to analyze the obtained products. Some of the physicochemical characteristics of samples were placed in the Supplementary material.

\section{Physicochemical Characteristics}

\section{FTIR}

The FTIR spectra (Fig. 4b), obtained after carbonization are typical of carbon structures. Based on the obtained spectra, it may be observed that, as a result of carbonization, functional groups of samples were degraded and almost all the stretching alcoholic bonds have been destroyed (including the $\mathrm{H}$-bonded ones), the $\mathrm{C}-\mathrm{H}$ 

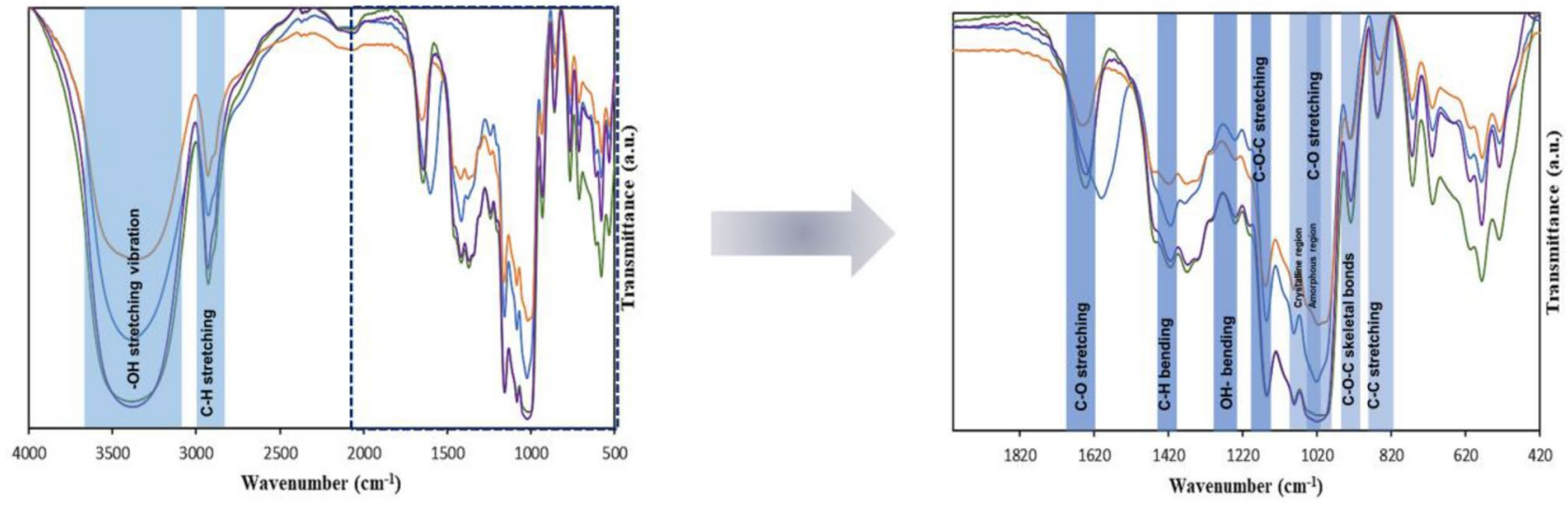

-PS - WS - $\mathrm{CS}$-RS
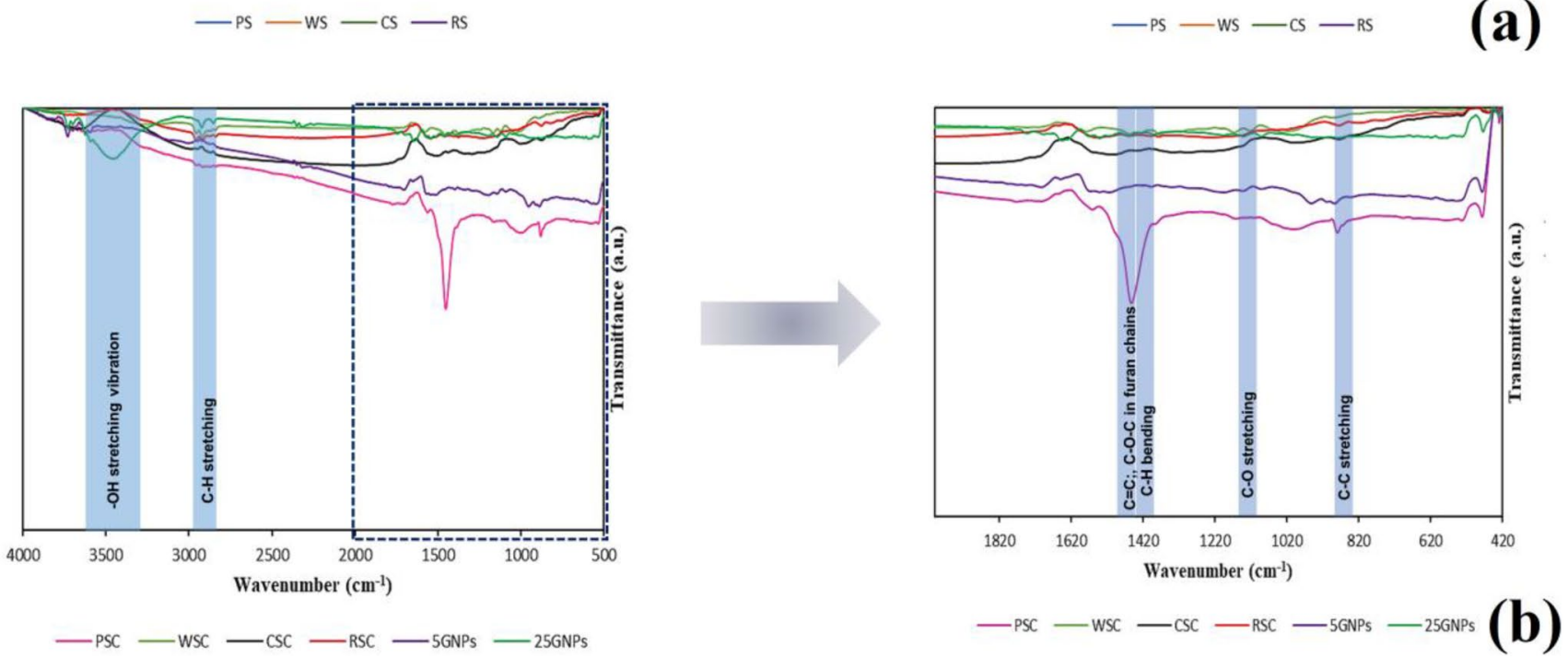

Fig. 4 The FTIR spectra of: a native starches; b SCs and GNPs

stretching bonds were significantly weakened and the $\mathrm{C}-\mathrm{O}$ and $\mathrm{C}-\mathrm{O}-\mathrm{C}$, despite $\mathrm{PSC}$, were not noticeable.

WSC presents slight $\mathrm{C}-\mathrm{C}$ bonds around the wavenumber of $851 \mathrm{~cm}^{-1}$. A part of the $4000-2300$ range is very similar to the graphite and graphene structures, which may confirm the presence of some identical groups within the materials [23]. According to the literature [24], vibrations for 1600 , and $1000-1450 \mathrm{~cm}^{-1}$ for PSC are associated with the occurrence of $\mathrm{C}=\mathrm{C}, \mathrm{C}-\mathrm{O}-\mathrm{C}$ bonds in the furan chains. It can, therefore, be argued that the visible peaks for PSC at the wavenumber of $1452 \mathrm{~cm}^{-1}$ can be understood as incomplete degradation of the furan ring. From another point of view, based on [25], part of the spectrum could be due to the spectrum of fullerenes $\mathrm{C}_{60}-\mathrm{COOH}$, also constituting different types of allotropic carbon. 25GNPs show a slight $\mathrm{OH}$ stretching vibration for $1345 \mathrm{~cm}^{-1}$ and 5GNPs have no $\mathrm{OH}$ bond. Furthermore, except PSC, the transmittance for all the functional groups after modification was equal to $9 \%$ maximum.
In the work [26], no peaks from chemical groups for pure GNPs were detected on the FTIR spectrum, which confirms the results obtained in the submitted work. Also, absence of the high intense peaks is seen in the manuscript, where microporous carbons derived from melamine and isophthalaldehyde were synthesized. Thus, the carbon materials in general, which are not modified, show the low intensity of absorbance of appropriate functional groups occurrence.

According to the reference [27] the main structure of the unmodified GNPs was benzene rings. There is an absorption peaks with obvious double-bonded $(\mathrm{C}=\mathrm{C})$ benzene rings were observe between 1600 and $1475 \mathrm{~cm}^{-1}$, which are perfectly seen for the PSC structure in our manuscript.

\section{The BET Analysis}

Figure 5 presents the BET analysis for the unmodified and carbonized starches and GNPs. The pristine materials were mesoporous and had truly small values of the surface area. 
Fig. 5 Comparison of the surface properties of carbonized and unmodified starches and GNPs a BET surface area; b pore size diameter; $\mathbf{c}$ pore volume

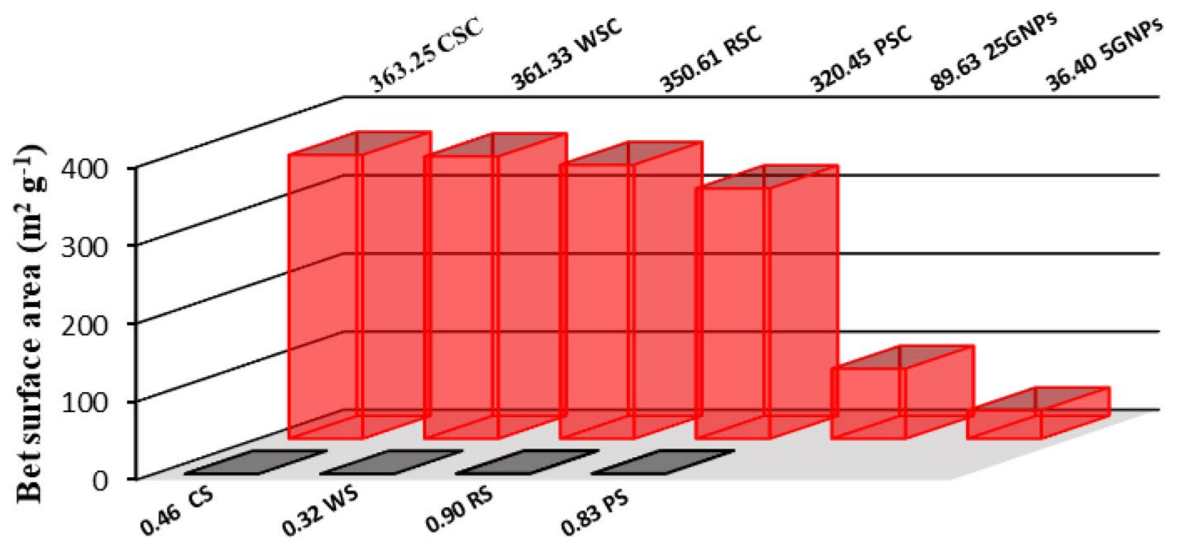

$\square$ Before carbonization

$\square$ After carbonization and GNPs

(a)

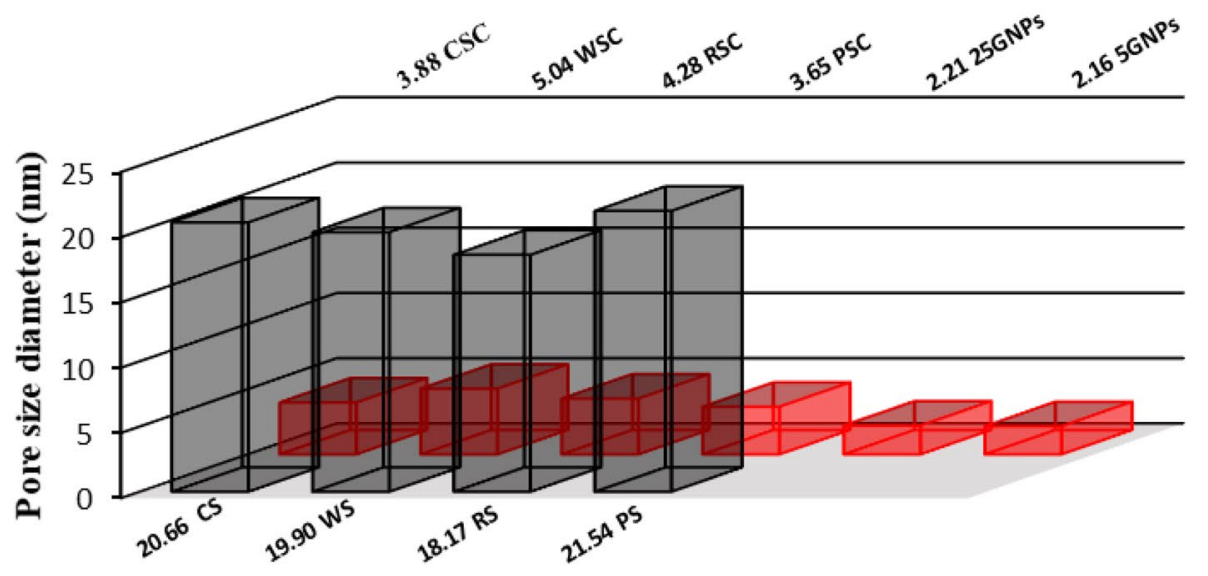

$\square$ Before carbonization $\square$ After carbonization and GNPs

(b)

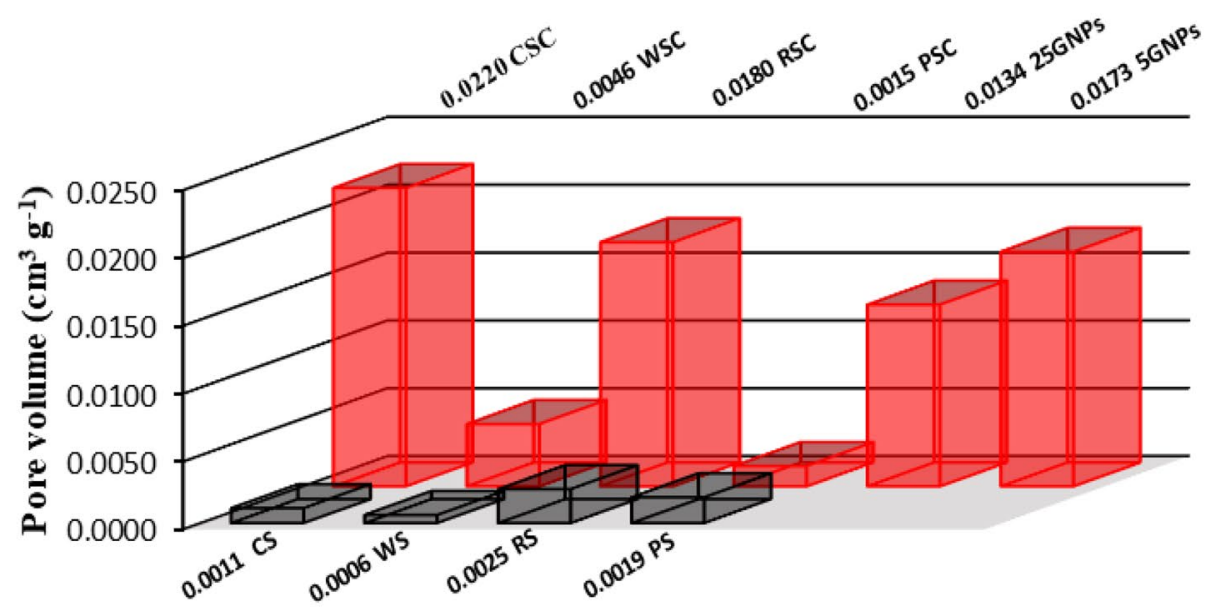

$\square$ Before carbonization $\square$ After carbonization and GNPs

(c) 
Despite the above, as for unmodified materials, they exhibited good electrochemical properties. Therefore, a thermal modification was carried out to improve the surface properties, hence the conductivity. Carbonized starches have a greater BET surface area than both GNPs, which makes the CSs more adsorptively active.

The surface area for the carbonized starches increases in the following order: PSC $<\mathrm{RSC}<\mathrm{WSC}<\mathrm{CSC}$, the pore diameter after modification in the following order: $\mathrm{PSC}<\mathrm{CSC}<\mathrm{RSC}<\mathrm{WSC}$ and the pore volume in the following order: $\mathrm{PSC}<\mathrm{WSC}<\mathrm{RSC}<\mathrm{CSC}$. All the pores are mesopore type on the verge of micropores, which may decrease the lithium ions diffusion coefficient. All the pore diameters of the SCs are smaller after carbonization, which also denotes the activation of the adsorption structure. The surface area of carbonized starches increases a hundred times compared to the unmodified ones and is many times higher than that of the GNPs for both particle sizes. The developed surface area makes the obtained carbon a great adsorption material and improves the electrochemical properties by facilitating the intercalation of the lithium ions in LIBs.

The smaller BET surface often indicates that the porous structure has a greater proportion of the meso- and macropores, and vice-versa with the developed surface areas, where the micropores dominate.

The BET specific surface area of graphene nanoplatelets used in work [28] was about $226.8 \mathrm{~m}^{2} \mathrm{~g}^{-1}$. GNPs could be also used as a pore definer and shrinkage inhibitor by using a straightforward sol-gel polymerization method and may reduce the induced linear shrinkage during drying step (from 15 to $5 \%$ ) and increase the pore surface area in case of nanocomposites [29].

\section{The SEM Measurement}

Before the carbonization process, all the pristine starches (Fig. 6c, f, i, k) were globular or polyhedral and the lithium ions were intercalated between those structures after the charging/discharging process forming a kind of sponge.

The obtained morphological structure after the carbonization of starches (Fig. 6a, b, d, e, g, h, j) confirms the obtained nanographene-like structure (Fig. 61, m). Carbon from all the starches is truly similar to the shape of the graphene nanoplatelets, but the SCs are more formed and visible. All SCs and GNPs are platelet-shaped and are identical as those found in the walls of the carbon nanotubes, but in a planar form. A similar shape of the 25GNPs was found in [30]. Almost identical SEM images for the CS were presented in the [31]. In our study, however, the carbonization process was carried out without any other modification such as the sol-gel processes, which makes our modification less demanding and expensive. In our study, wrinkled and ultrathin sheets could also be seen after carbonization. Here, the comparison is carried out between the graphene nanosheets and carbon from different starches, but the similarity to highly graphitized hard carbon rather than to pyrolytic amorphous carbon materials could also be observed $[31,32]$. It should be also noted that in its structure graphite contains graphene layers and it could be the reason for the structures to appear morphological to become similar. Graphene nanoplates (GNPs) are thin flat particles, that consist of single and few-layer graphene mixed with thicker graphite, thus, they assume a form between graphene and graphite [33]. In [34] similar SEM images were obtained for few-layer graphene, synthesized via the liquid exfoliation process, as observed for carbon from various starches, which may confirm the obtained morphological graphene-layered structure. In this study, carbon (CS) has a dense lamellar structure and the surface is visibly smooth, more mechanically durable, thicker and not as full with the morphological defects compared to GNPs.

Similar to the structures obtained in this manuscript, morphological images were shown in [35] for GNPs. The graphene nanoplatelets used have a narrow thickness distribution; it is worth noting that the thickness is an average of the dimension of the graphene nanoplatelets along the direction perpendicular to the carbon layers.

\section{Electrochemical Properties}

The most important challenges for the curent generation include solving the environmental problems by designing products and chemical processes in such a way as to reduce or eliminate the use of hazardous substances. One of the basic tools for the implementation of this principle is the development of methods using the phenomenon, e.g. catalysis and development of electrochemical methods. It is important to search for new materials possessing valuable and often unusual properties that can find potential application, inter alia, in material engineering, biotechnology, biomedicine or in energy storage devices.

\section{Cyclic Voltammetry}

Cyclic voltammetry (CV) is a powerful and popular electrochemical technique commonly employed to investigate the reduction and oxidation processes of molecular species. CV is also invaluable in studying the electron transfer-initiated chemical reactions that include catalysis. When the transfer of electrons at the electrode surface is slow compared to the mass transport, the process is described as "electrochemically irreversible" (then the curves in the cycles do not exactly match). In the case of the analyzed materials, it is quite the opposite. 


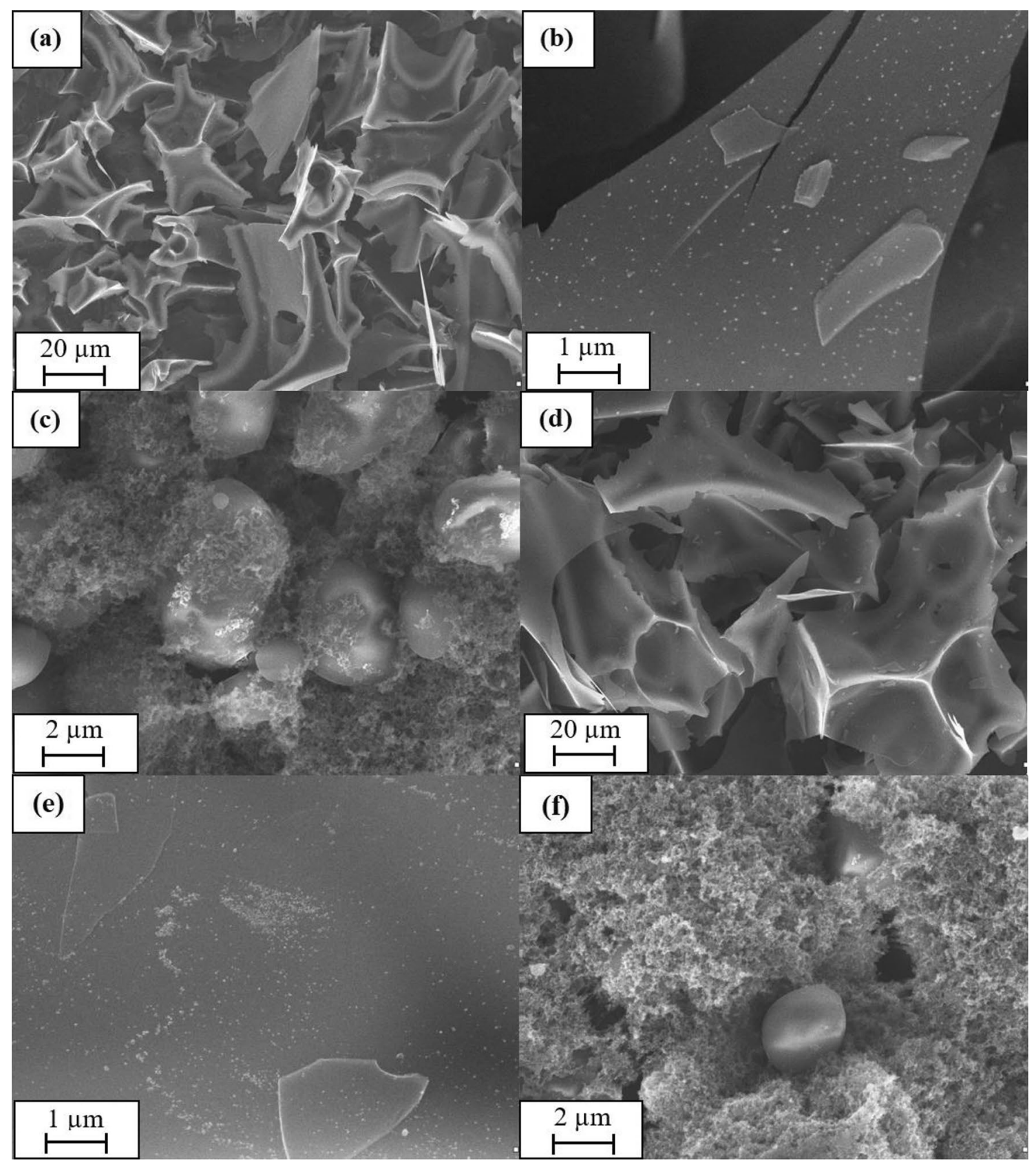

Fig. 6 SEM of a, b CSC; $\mathbf{c ~ C S ; ~ d , ~ e ~ W S C ; ~ f ~ W S ; ~} \mathbf{g}$, h RSC; i RS; j PSC; $\mathbf{k}$ PS; 1 5GNPs; $\mathbf{m}$ 25GNPs

Figure 7a-g show the obtained potentiodynamic results of the carbonized starches and graphene nanoplatelets at the scan rates of 1 and $2 \mathrm{mV} \mathrm{s}^{-1}$. All the results exhibit high electrochemical cyclic stability.

It could be easily seen that the best results were achieved for the CSC and at the $2 \mathrm{mV} \mathrm{s}^{-1}$ current the values were up to $7.4 \times 10^{-2} \mathrm{~A}$ during oxidation (Fig. $7 \mathrm{~b}$ ). An oxidation peak for the CSC could be seen at a potential of $0.86 \mathrm{~V}$, a reduction peak at the potential of $0.92 \mathrm{~V}$, which denotes a slight presence of overpotentials and a perfect change of polarization after the oxidation process. The higher the scan rate, the higher currents could be obtained. In comparison with the GNPs (Figs. 7e, f), the most similar (to CSC) cycle shape was observed for the 5GNPs (Fig. 7e).

The oxidation and reduction peaks for the 5GNPs were at the voltages of $1.02 \mathrm{~V}$ and $0.8 \mathrm{~V}$ respectively. Despite the similar shape, the CSC showed much higher currents compared to the graphene nanoplatelets. However, the reduction peaks for the 5GNPs were slight and the CSC exhibited a much more visible reduction peak due to the lithiation process. Also, higher overpotentials could be seen in Fig. 7e. The RSC (Fig. 7a) also shows the well 


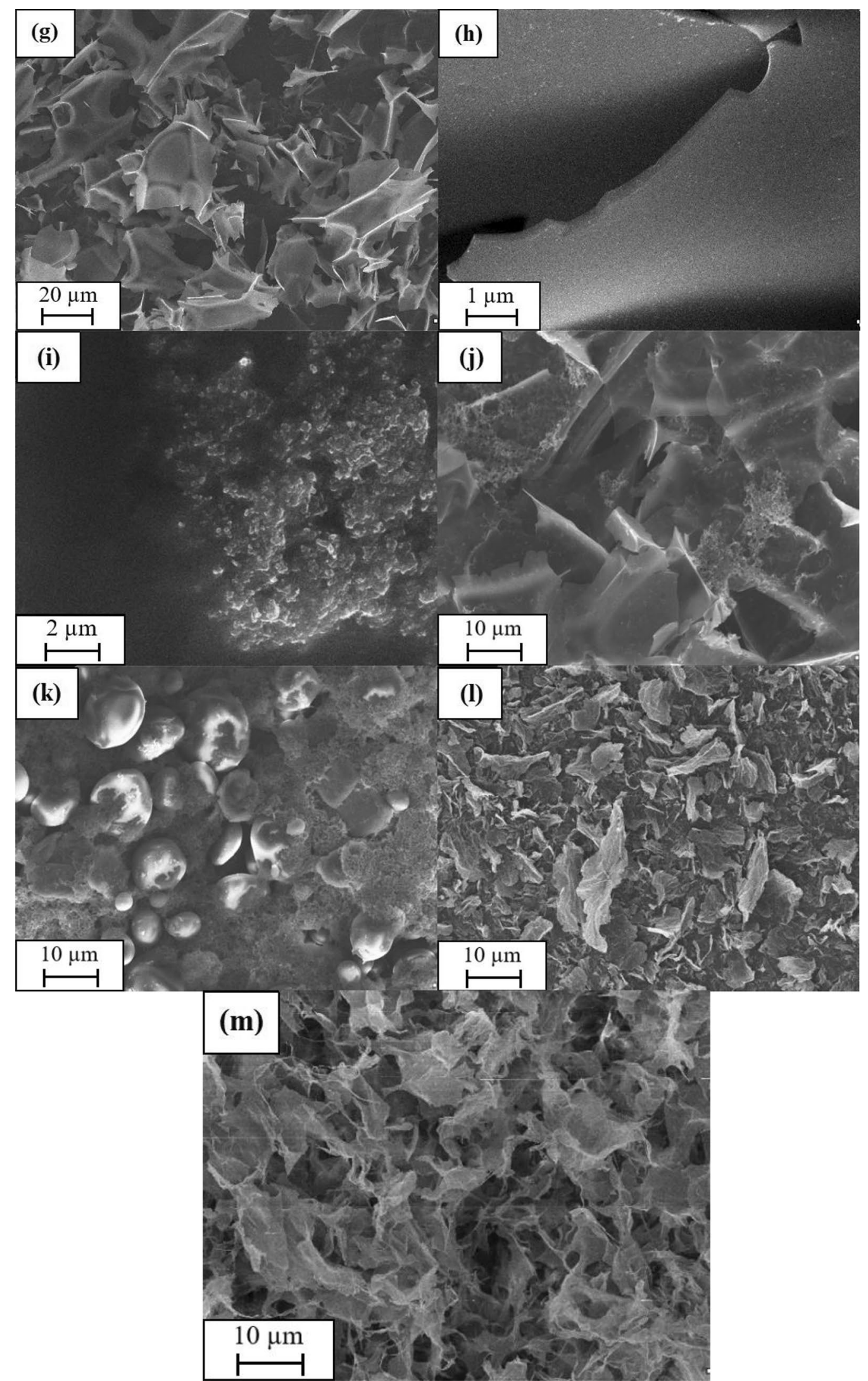

Fig. 6 (continued) 
Fig. 7 Cyclic voltammetry of a RSC; b CSC; $\mathbf{c}$ PSC; d WSC; e $5 \mathrm{GNPs} ; \mathbf{f} 25 \mathrm{GNPs} ; \mathbf{g}$ comparison for $2 \mathrm{mV} \mathrm{s}^{-1}$ for the SCs and GNPs
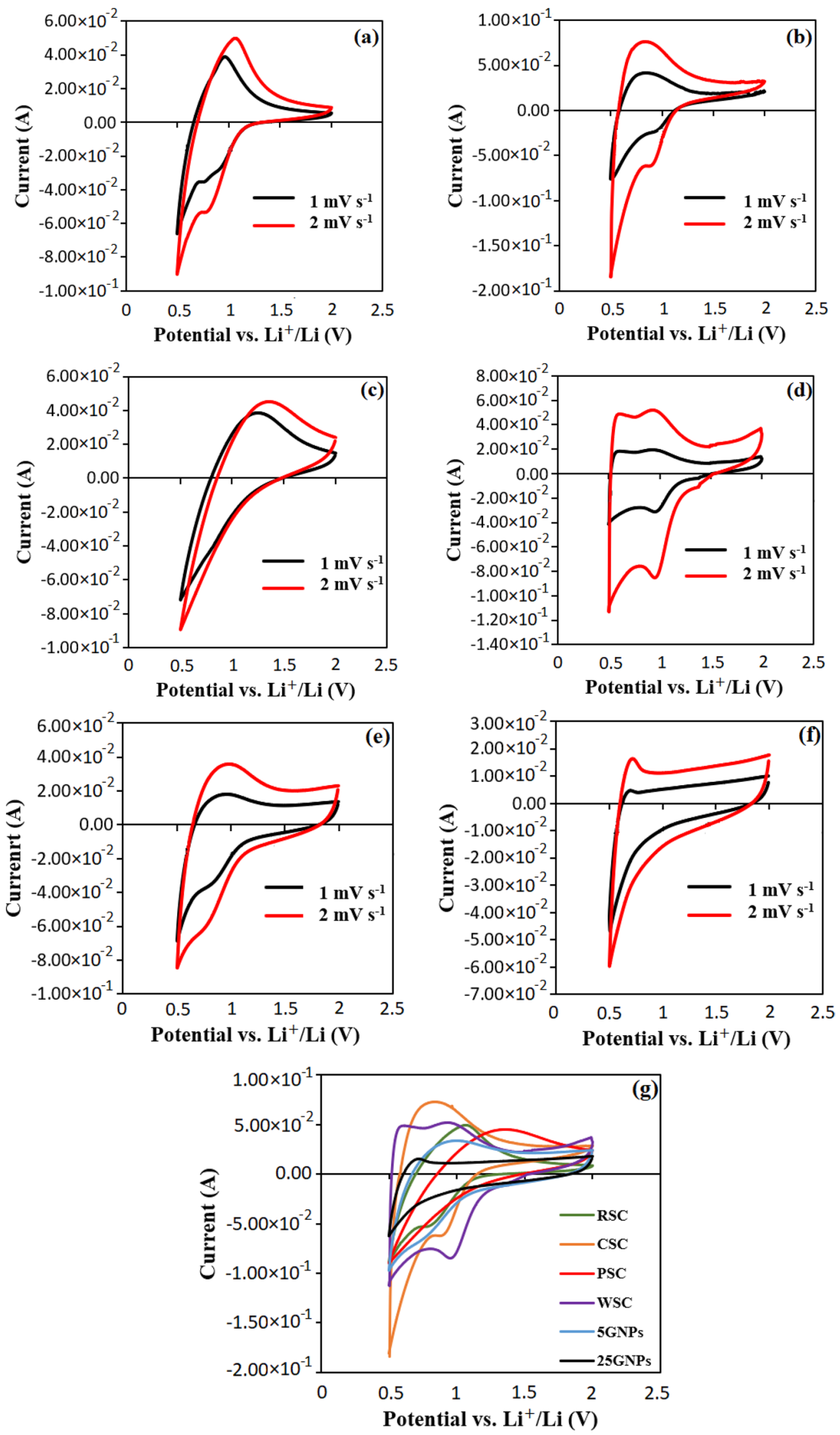
visible oxidation and reduction peaks at the potential of $1.05 \mathrm{~V}$ and $0.82 \mathrm{~V}$ for the scan rate of $1 \mathrm{mV} \mathrm{s}^{-1}$, respectively. It should be noted that for the scan rate of $2 \mathrm{mV}$ $\mathrm{s}^{-1}$, an oxidation peak was slightly shifted towards the potential of $0.96 \mathrm{~V}$. The PSC (Fig. 7c) presents only the oxidation peaks, which are wide, at the voltage of $1.23 \mathrm{~V}$ and $1.34 \mathrm{~V}$ for the scan rate of $1 \mathrm{mV} \mathrm{s}^{-1}$ and $2 \mathrm{mV} \mathrm{s}^{-1}$, respectively. This result is very similar compared to that of the 25GNPs (Fig. 7f). In both cases, there is no reduction peak due to the lithiation process. The oxidation peak for the 25GNPs is much sharper than that of the PSC. Despite that, the PSC shows much higher currents and in comparison to the GNPs (Fig. 7g) and a less capacitor-like cycle shape. After the disappearance of the oxidation peak (after oxidation) for the $25 \mathrm{GNPs}$, the currents increased for higher potentials and the $\mathrm{CV}$ plot became more rectangular, which is more common for capacitors. The absence of the reduction peak in Fig. $7 \mathrm{c}$, f denotes a nonfaradaic reaction, hence we are dealing here with the capacity of the double electrical layer. Thus, the fact that voltammetric curves have current peaks on one side only (which means either an oxidation or a reduction reaction occurs) indicates the irreversible nature of the reactions and it may be certainly assumed that such material does not exhibit useful properties for application as the anode material in galvanic cells. Moreover, it should be noted that the presence of the faradaic and nonfaradaic peaks is attributed to the pseudocapacitance, hence an additional additional capacitance could be observed. In all other cases, the faradaic reactions due to oxidation and reduction are clearly seen and the windows are not capacitor-like, thus, the CV plots are characteristic of the faradaic reactions in the lithium-ion cells - the lithation and delithiation as well as materials appropriate for the LIB galvanic cells.

Moreover, because there is no literature data that confirm the reactions that may occur during the lithiation and delithiation processes and the GNPs exhibit a high similarity of properties to the CNTs (carbon nanotubes) and the GNS (graphene nanosheets), the reaction proposed in Eq. 1 during the charge may occur.

$\mathrm{xLi}^{+}+\mathrm{xe}^{-}+\mathrm{C}_{\mathrm{y}} \leftrightarrow \mathrm{Li}_{\mathrm{x}} \mathrm{C}_{\mathrm{y}}$

where $x$ is the number of lithium ions, that intercalate during the charge process, and $y$ is the number of carbon, to which lithium intercalates. For the graphene nanosheets, it is a value equal to 3 [36] and for the SWNTs (single-walled carbon nanotube) $y$ may reach $60,36,20$ for the particle diameter of $0.7,0.47,0.39 \mathrm{~nm}$, respectively [37]. In general, there is a greater similarity to the GNS, hence, it could be more accurate to use this amount of carbon to predict the lithium ions intercalation-deintercalation mechanism for the SCs and the GNPs.

\section{Electrochemical Impedance Spectroscopy}

The Nyquist plots are tested by the electrochemical impedance spectroscopy (EIS) as shown in Fig. 8. $\mathrm{R}_{\mathrm{S}}$ is the intersection on the real axis at high frequency according to the electrode and electrolyte resistance and $\mathrm{R}_{\mathrm{ct}}$ is the diameter of the semicircle formed by the intersection of the plot and the real axis when referring to the load transfer resistance. At the lower frequency region, the diameter of the semicircle formed by the curve represents the internal resistance of the charge transfer $\left(\mathrm{R}_{\mathrm{ct}}\right)$ [38]. $\mathrm{W}_{0}$ is the Warburg impedance corresponding to semi-finite diffusion. CPE is a solid phase element whose exponents $\mathrm{n}=0.5$ and 1 refer to a resistor, a diffusion-controlled process (Warburg element) and an ideal capacitor [39]. From the high-frequency region to the midfrequency region (semicircular part), the $\mathrm{R}_{\mathrm{s}}$ value decreases slightly after a large number of cycles, which indicates better electrode charge transfer kinetics after cyclic activation [40]. In one of the works [41], the authors note that in the low-frequency range, the curves close to the vertical denote a good ability to diffuse ions, which is consistent with the capacitive contribution of the ion diffusion [42]. However, in the low-frequency area, it turns out that the slope decreases, which denotes an increase in the resistance in the mass transfer process, which, in turn, is responsible for the capacity decay [39].

The Fig. 8a-f present the EIS spectra for the raw and carbonized starches and the GNPs and Fig. 8g shows the equivalent circuit used in this study. In all cases, the Nyquist plots consist of two parts: a semi-circle in a high-middle frequency region and a linear curve in a low-frequency region. A presence of a semi-circle is associated with the exchange of charges between the electrode and the electrolyte $\left(\mathrm{R}_{\mathrm{ct}}\right)$ and the SEI layer formation $\left(\mathrm{R}_{\mathrm{SEI}}\right)$. After the carbonization, the semi-circle becomes smaller because the cyclic stability test (CV) facilitates the system charging and discharging and makes the system more stable after the cycles.

Thus, due to the charge transfer and the SEI (solid-electrolyte interphase) formation the resistances become smaller and the major process is the diffusion. The linear part of the plot confirms the presence of the Warburg line, which is due to the diffusion of the lithium ions in the bulk active mass. The more SEI is formed, the more stable the system becomes because it mainly protects the electrodes against corrosion and maintains good cycling characteristics and battery safety. Furthermore, a stable SEI is critical to achieving the high initial coulombic efficiency [43]. However, as the SEI expands, numerous defects and grain boundaries are created, which could lead to a significant anisotropic diffusivity of $\mathrm{Li}$ toward the electrode surface. This may result in an uneven Li delivery to the electrode/SEI interface and cause a decrease in the performance of the cell [44]. The smallest resistances are observed for the CSC, which is 
Fig. 8 EIS of: a CSC; $\mathbf{b}$ PSC; c WSC; d RSC; e 5GNPs;

f $25 \mathrm{GNPs}$; $\mathbf{g}$ the equivalent circuit for the impedance measurements

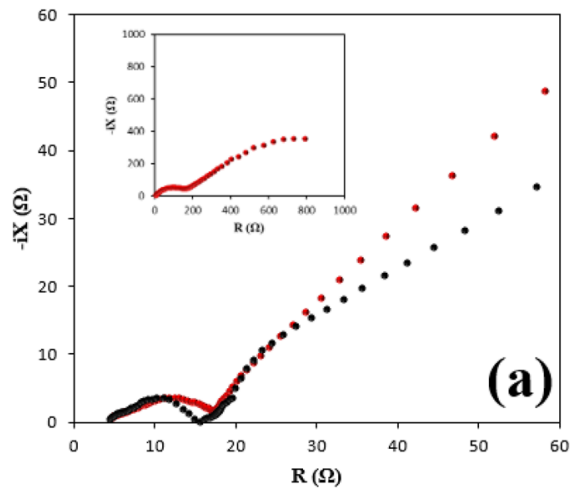

- Before Stability - After Stability

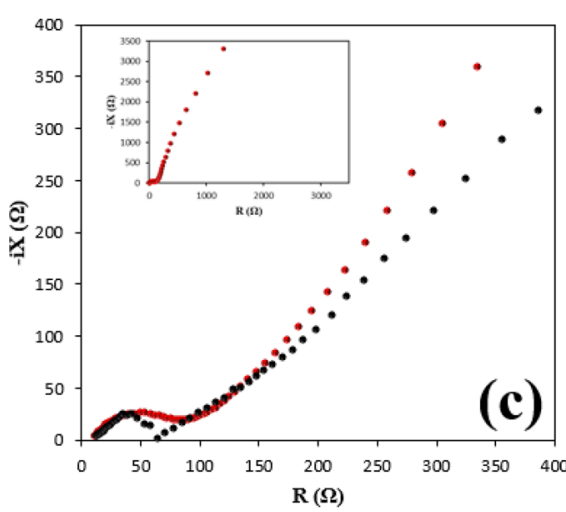

- Before Stability - After Stability

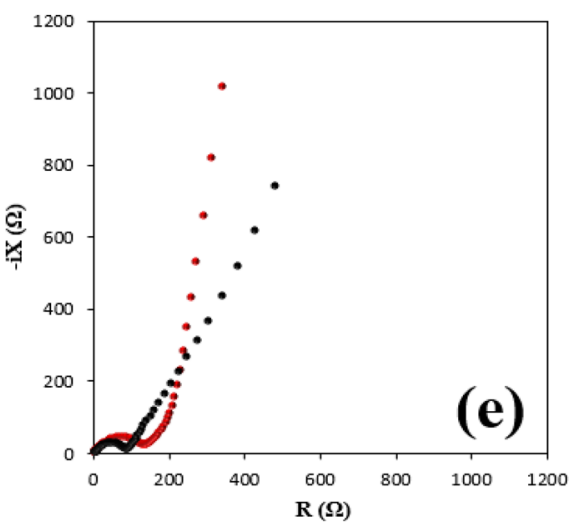

- Before Stability - After Stability

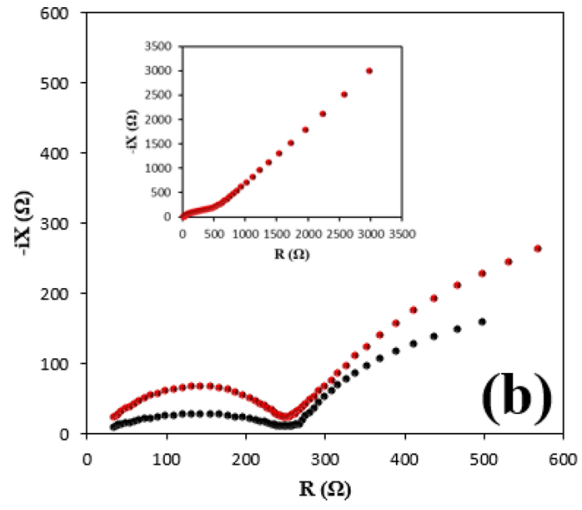

- Before Stability - After Stability

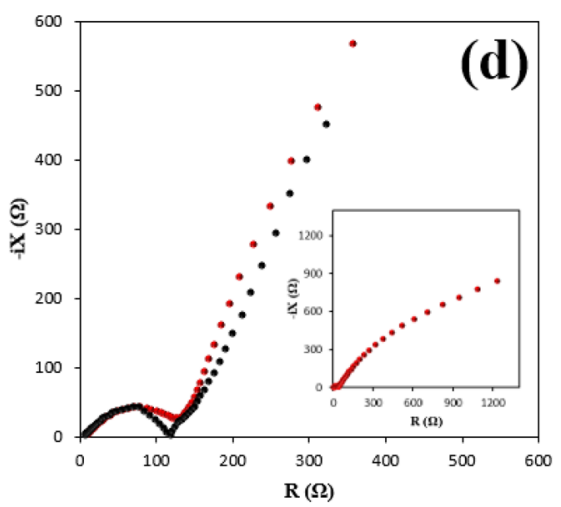

- Before Stability - After Stability

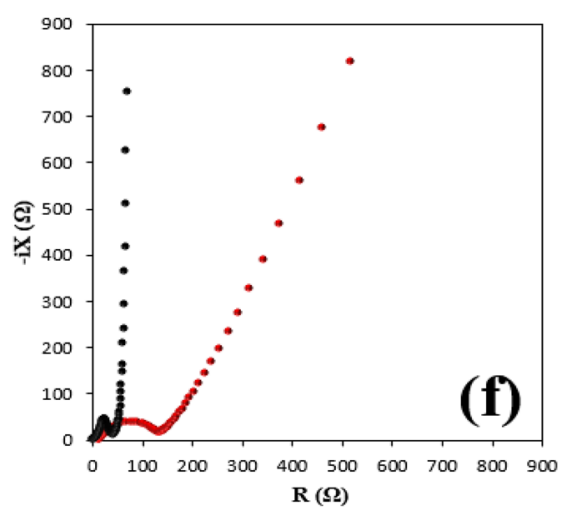

- Before Stability -After Stability

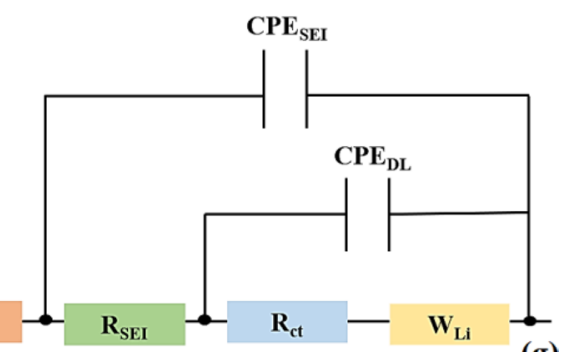


confirmed by the CV test (Fig. 8b) and the highest values of current for the same range of potentials of all the measured samples. Moreover, it could be easily observed that the most capacitor-like EIS is presented for the 25GNPS after the $\mathrm{CV}$ test, but before the stability test, the right angle for the LIBs of the Warburg line was well visible, but the semicircle reached higher resistances. This phenomenon can be associated with the intercalation of the lithium ions followed by their permanent accumulation or with the charging of a double electrical layer associated with the non-faradaic reactions characteristic of the electrochemical capacitors, which is confirmed by the CV (Fig. 8f) through the presence of only a single oxidation peak due to the delithiation and no peak attributed to the lithiation (reduction reaction). In all cases, the Warburg lines have angle values in the range of $35-45^{\circ}$, hence the best conditions for the diffusion of the $\mathrm{Li}$ ions are fulfilled. The flattest trend of the Warburg line is observed for the PSC and the spectra are truly similar to graphite [34] and, what is more, the values of resistances and impedances are comparable. For other SCs, particularly the CSCs, the spectrum is similar to few-layer graphene, but in our manuscript the impedances exhibit smaller values, which makes our material more electrochemically active [34]. The resistances due to the $\mathrm{SEI}$ formation $\left(\mathrm{R}_{\mathrm{SEI}}\right)$ before the stability test are in the range of 5-17 $\Omega, 34-233 \Omega, 13-72 \Omega$, $10-125 \Omega$ for CSC, PSC, WSC, RSC, respectively. After the stability test, those resistances are in the limits of 5-15 $\Omega, 34-233 \Omega, 13-59 \Omega, 10-110 \Omega$ CSC, PSC, WSC, RSC. For the 5GNPs, the SEI forms for resistances in the range of 6-148 $\Omega$ and 6-87 $\Omega$ before and after the stability test, respectively. For the $25 \mathrm{GNPs}$, this phenomenon occurs in the limits of 13-128 $\Omega$ and 1-25 $\Omega$ before and after CV. It could be obviously seen that for all the carbonized starches, small resistances (caused by the electrolyte) are visible before the semi-circle begins. In the case of the PSC, the resistances due to the charge transfer and the SEI formation have the highest real values and after the stability test, the semi-circle becomes flatter and so do the impedances. $R_{\mathrm{ct}}$ is equal to $17,233,72,125 \Omega$ and $15,233,59,110 \Omega$ for CSC, PSC, WSC, RSC, before and after CV, respectively. For the GNPs, the charge transfer occurs at 148, $128 \Omega$ and 87, 25 $\Omega$ before and after CV for 5GNPs and 25GNPs. However, for almost every anode system, after stabilization, resistances due to the charge transfer shift to smaller values, thus, increasing the electrochemical intercalation properties by increasing the diffusion control and decreasing the kinetic part. After the charge exchange in every case, the Warburg line occurs and the diffusion of lithium ions and the accumulation is the principal mechanism. After carbonization (Fig. 8a-d), resistances and impedances visibly decrease, which may be due to a much more specific developed surface area of carbon, smaller pore diameter and higher pore volumes, as confirmed by the BET test (Fig. 5a-c). All the
BET data were appointed in the supplementary section and the specific BET surface areas were equal to $363.25,361.33$, $350.61,320.45,89.63,36.40 \mathrm{~m}^{2} \mathrm{~g}^{-1}$ for CSC, WSC, RSC, PSC, 25GNPs, 5GNPs, respectively. Thus, the carbonization process activated the starch derivates electrochemically and made them better electric conductors even compared to GNPs in both diameter cases.

For all the samples after the stability test, the diffusion coefficient $\mathrm{D}_{\mathrm{Li}+}\left(\mathrm{cm}^{2} \mathrm{~s}^{-1}\right)$ was appointed caused by the Warburg lines in the Nyquist plots (based on Fig. 8). In literature $[34,45]$ researchers used Eqs. 2 and 3.

$D_{L i^{+}}=\frac{R^{2} T^{2}}{2 A^{2} n^{4} F^{4} C^{2} \sigma h 2}$

In the Eq. (2) $\mathrm{R}$ is the gas constant equal to $8.314 \mathrm{~J} \mathrm{~mol}^{-1} \mathrm{~K}^{-1}$, T- standard temperature $(298 \mathrm{~K}), \mathrm{A}$-effective surface area of the electrode $\left(1.54 \mathrm{~cm}^{2}\right), \mathrm{n}$-electronic transport ratio during oxidation, F-Faraday's constant $\left(96,500 \mathrm{C} \mathrm{mol}^{-1}\right)$, $\mathrm{c}$-molar density of Li-ion in the electrode $(0.001 \mathrm{~mol}$ $\left.\mathrm{cm}^{-3}\right), \sigma$-constant from the Warburg line $\left(\Omega \mathrm{s}^{-1 / 2}\right)$

$Z^{\prime}=R_{D}+R_{L}+\sigma \omega^{-\frac{1}{2}}$

To obtain the constant $\sigma$, the plots $Z^{\prime}\left(-Z^{\prime \prime}\right)$ versus $\omega^{-1 / 2}$ for the diffusion resistances were created and the slope was equal to $\sigma$. Table 2 shows the determined values of $\mathrm{D}_{\mathrm{Li}+}$ and $\sigma$.

According to Eq. 2, in order to determine the diffusion coefficient, in Eq. the reference is made to the surface area of electrode A, not to the specific surface area of the active carbon material. According to the Fick's diffusion laws, moving through a surface is perpendicular to the direction of the movement of the particles, which is the main reason, why we use the area of the electrode for the calculations. However, when it comes to the diffusional movement of the ions through the porous structure of the electrode material, it is important to know the BET specific surface area, because it tells a lot about the environment, in which this mass transport occurs. As for the relationship between the diffusion coefficient and the porous structure or the development of the BET specific surface area, in the case of

Table 2 A diffusion coefficient calculated from the impedance data based on Eqs. (2-3)

\begin{tabular}{lcc}
\hline Sample & $\sigma\left(\Omega \mathrm{s}^{-1 / 2}\right)$ & $\mathrm{D}_{\mathrm{Li}+}\left(\mathrm{cm}^{2} \mathrm{~s}^{-1}\right)$ \\
\hline CSC & 13.98 & $7.64 \times 10^{-11}$ \\
PSC & 222.09 & $3.03 \times 10^{-13}$ \\
WSC & 81.63 & $2.24 \times 10^{-12}$ \\
RSC & 111.31 & $1.20 \times 10^{-12}$ \\
25GNPs & 140.15 & $7.60 \times 10^{-13}$ \\
5GNPs & 52.47 & $5.42 \times 10^{-12}$ \\
\hline
\end{tabular}


larger pore sizes (meso- and macropores), the diffusion is more efficient/runs smoothly in contrast to the microporous structure where the space, through which the $\mathrm{Li}^{+}$ions may diffuse, is much smaller. In general, as a consequence of the potential resistance, the velocity of the ions movement within the diffusion is lower. It should also be noted that more important is the active surface area compared to the specific surface area because we primarily consider the part of the electrode surface that is directly involved in the electrochemical processes, i.e. the $\mathrm{Li}^{+}$ion sorption. For various reasons, the active surface area is not always the same as the specific surface area, because the entire surface may not be involved in the mass exchange. It heavily depends on the ion size-pore relationship.

Based on Table 2, the highest value of the diffusion coefficient within the SCs was obtained for the CSC and the smallest for the PSC, which CV (diffusion control) and EIS confirm (Figs. 7, 8). According to the literature data, $\mathrm{D}_{\mathrm{Li}+}$ in carbon materials at a room temperature is between $10^{-9}$ and $10^{-11} \mathrm{~cm}^{2} \mathrm{~s}^{-1}[46,47]$. In the literature [48] researchers achieved values up to $4.39 \times 10^{-11} \mathrm{~cm}^{2} \mathrm{~s}^{-1}$ and, for fewlayer graphene, up to $2.67 \times 10^{-9} \mathrm{~cm}^{2} \mathrm{~s}^{-1}$. In our work, the most accurate value was reached for the CSC. It should also be noted that those diffusion coefficients are higher for the commercial carbon materials and depend on the synthesis process.

According to [48], a good lithium ion diffusion coefficient of the material contributes to reducing the electrochemical and concentration polarization in the charge-discharge process. It is also confirmed by the small overpotentials in the CV test (Fig. 7).

It is also well known that the Li diffusion occurs through the numerous open channels formed by the grain boundaries of the SEI where this mass transport occurs generally faster than in the neighboring crystalline regions within the grain interiors [44].

\section{Charge-Discharge Test}

Zhao et al. reported that disordered graphene nanosheets exhibited high reversible capacities of 794-1054 $\mathrm{mAh} \mathrm{g}^{-1}$ and a good cyclic stability, which may be due to the additional reversible storage sites such as edges and other defects such as vacancies [49, 50].

Figure 9a-c shows the proposed mechanisms for the lithium storage between the GNPs and the electrolyte. According to Fig. 9a, if the graphene structure has defects, the solid electrolyte interface (SEI) forms easier. Higher scan (a)

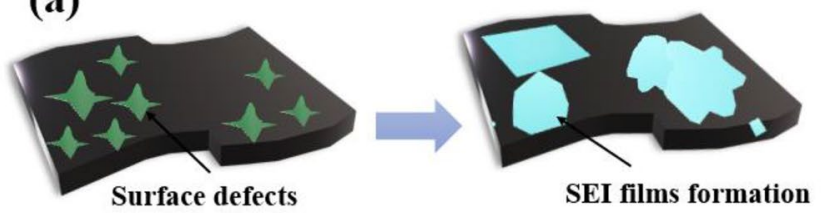

(b)
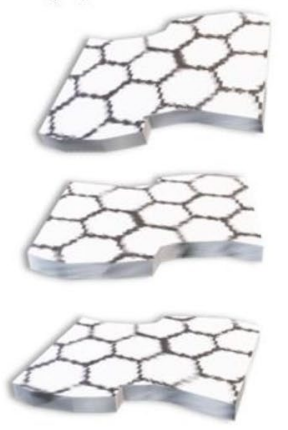
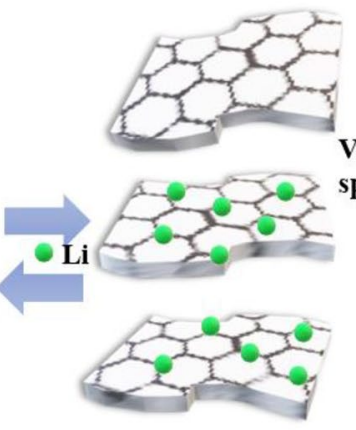

(c)

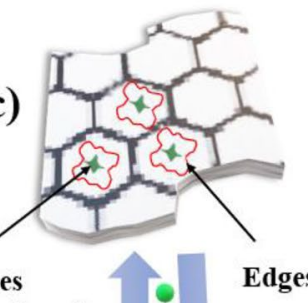

$\mathrm{p}^{2}$ nanodomains

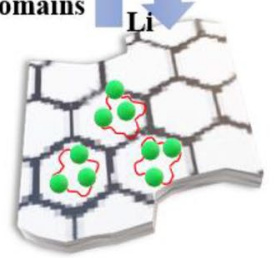

(d)

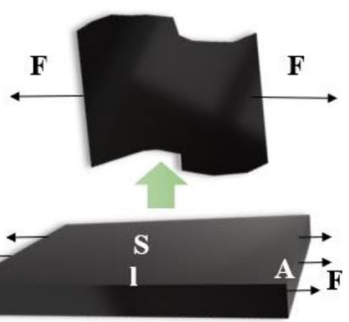

Graphene Nanoplatelets (GNPs)

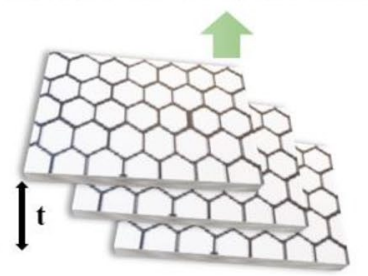

Few layer graphene

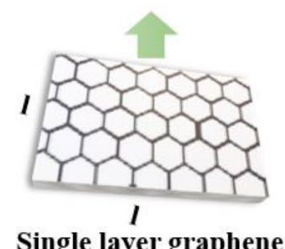

Fig. 9 Characteristics of the surface interaction between the GNPs and the electrolyte for a irreversible Li storage at the interface between the GNPs and the electrolyte; $\mathbf{b}$ reversible Li storage between planes; $\mathbf{c}$ reversible $\mathrm{Li}$ storage at edge sites and internal defects of the nanodomains embedded in the GNPs, $\mathbf{d}$ sketch diagrams composition unit and model of the GNPs [51, 52]; " $t$ " denotes thickness and "l" is the side length 
rates during the $\mathrm{CV}$ test make the layer flatter. Graphene and its derivates demonstrate a large energy loss during the charge-discharge process and it could be associated with the morphological defects and is confirmed by the voltage profiles in Fig. 10d.

Figure $9 \mathrm{~b}$ presents the reversible intercalation process during the charge-discharge process, which is always attributed to the formation of the ionic bonds. Moreover, if a structure possesses defects such as vacancies, reversible lithium storage at those gaps occurs. Irreversible Li storage may occur when there is little difference between the size of the gap and the lithium (cation) ion.

Afterwards, Li may form another network node, thus, briefly increasing the electrochemical conductivity, but blocking the place for intercalation of the subsequent ions in the next cycles of the cell work and decreasing the cell life, which may occur for the GNPs. Based on the literature [43], the electrochemical performance of the CNTs depends on the presence of impurities, structural defects, and the nature of graphitization, which confirms the truly important phenomenon of defects in the carbon structure and its impact on the electrochemical behavior.

Figure 9d shows the structure of the GNPs, the mechanical strength and the mode of action of various forces proposed by Du, X., Du, W., et al. Graphene nanoplatelets
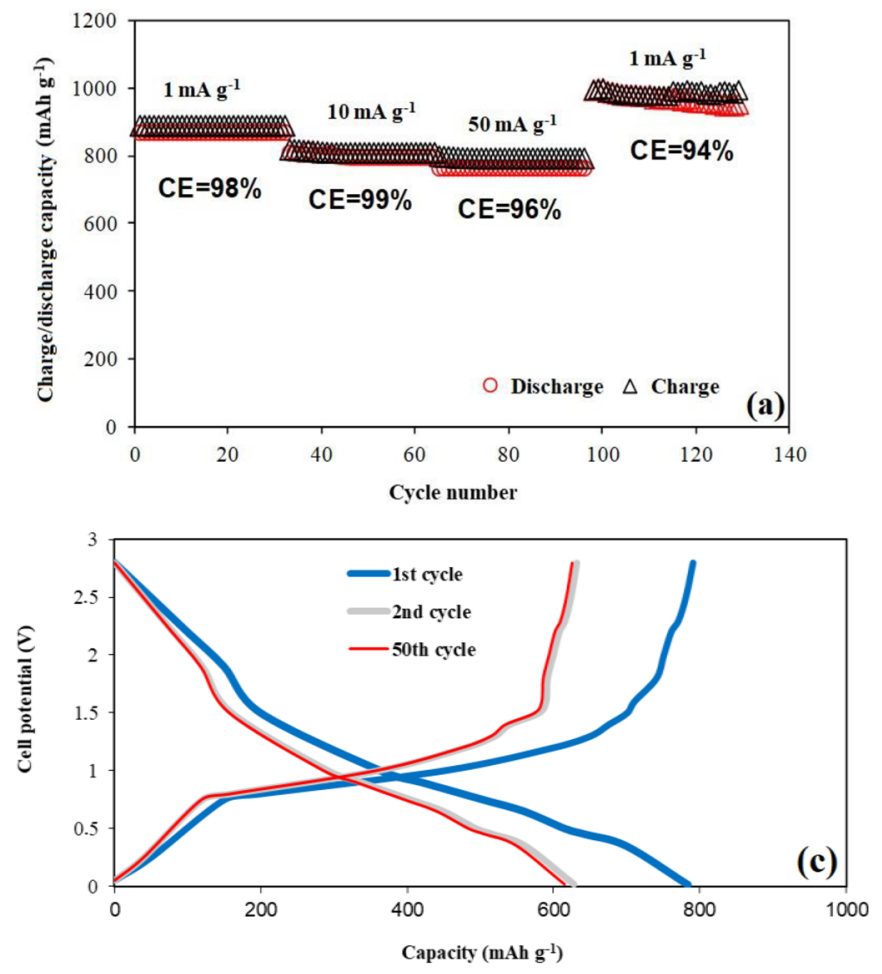

Fig. 10 Rate performance test of a the CSC at different current densities b CSC, 5GNPs, 25GNPs at $10 \mathrm{~mA} \mathrm{~g}^{-1} \mathbf{c}$ the selective discharge/ charge voltage profiles of the CSC sample at the current density of 10 consist of several single layers of graphene, which are stuck to each other as a square plate. Moreover, the interfacial area (S) and the cross-sectional area (A) may be estimated with $2(1+\mathrm{t}) 1$ and $1 \times \mathrm{t}$, respectively. In [50], $11 \sim 10$ $\mu \mathrm{m}$ diameters were obtained and $\mathrm{t}$ was $\sim 4.2 \mathrm{~nm}$, which corresponded to the average sizes of the GNPs determined by the SEM and HRTEM measurement techniques.

To obtain the capacitive properties of the SCs and the GNPs, a cell charge-discharge test was performed. Owing to the best electrochemical properties obtained for the CSC in the CV test, the EIS tests, the highest diffusion coefficient among the other SCs, the test results at different current densities and a comparison to the 5GNPs and 25GNPs have been presented in Figs. 10a-d presented only for the CSC.

The current density of the battery material increases and the specific capacity decreases (Fig. 10a). For all the cases, the values of the charging capacity almost overlapped the capacities at the discharge after the subsequent cycles, which indicates a high cyclic stability. For the current densities equal to $1 \mathrm{~mA} \mathrm{~g}^{-1}, 10 \mathrm{~mA} \mathrm{~g}^{-1}, 50 \mathrm{~mA} \mathrm{~g}^{-1}, 1 \mathrm{~mA} \mathrm{~g}^{-1}$, the highest values of discharge capacity were equal to 820,800 , 790, $1000 \mathrm{mAh} \mathrm{g}^{-1}$, respectively. The trend of the capacity behavior at $1 \mathrm{~mA} \mathrm{~g}^{-1}$ demonstrates the restorability of the cell.
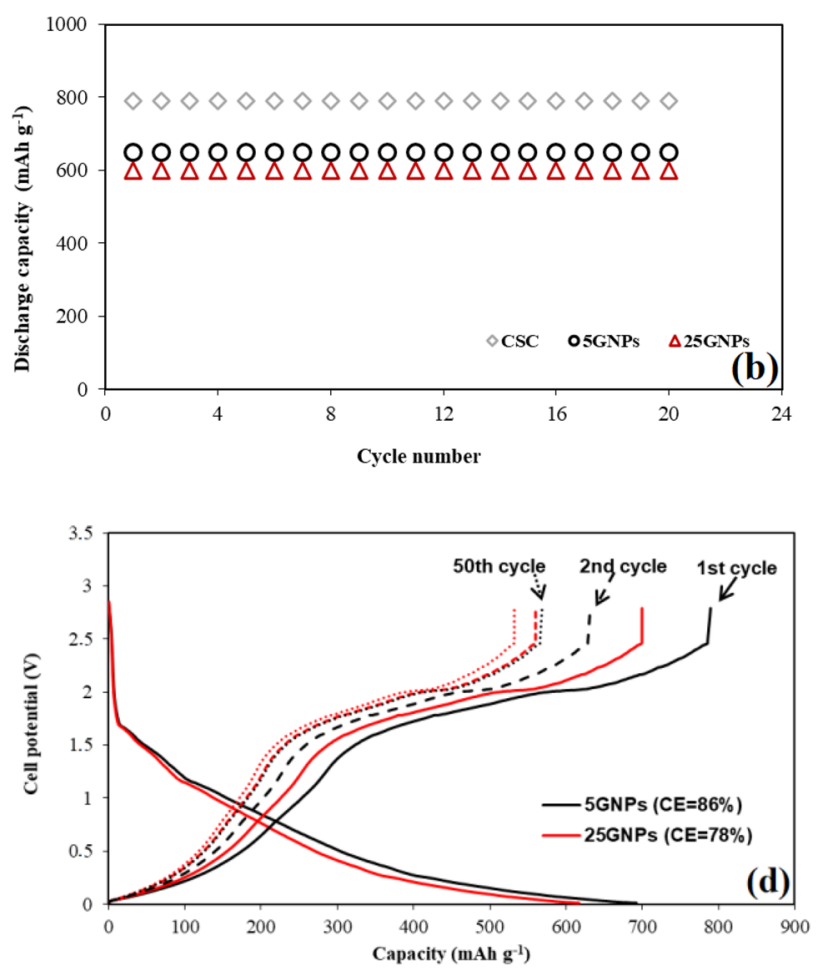

$\mathrm{mA} \mathrm{g}^{-1} \mathbf{d}$ the voltage profiles of the 5GNPs and 25GNPs at the current density of $10 \mathrm{~mA} \mathrm{~g}^{-1}$ 
Figure $10 \mathrm{~b}$ presents the comparison of the CSC, the $5 \mathrm{GNPs}$, and the 25GNPs for the current density of $10 \mathrm{~mA}$ $\mathrm{g}^{-1}$ after 20 cycles for all the probe capacitance values that were stable after the cycles and equaled $600,650,790 \mathrm{mAh}$ $\mathrm{g}^{-1}$ for the 25GNPs, the 5GNPs and the CSC, respectively. Thus, the best capacity results were obtained for the CSC. The discharge capacities for all the cases exhibit much higher values than for graphite as classic anode material for the LIBs (372 $\mathrm{mAh} \mathrm{g}^{-1}$ ).

The voltage profiles for the discharge/charge process after the $1 \mathrm{st}, 2 \mathrm{nd}, 50$ th cycle at the current density of $10 \mathrm{~mA} \mathrm{~g}^{-1}$ for the CSC have been presented in Fig. 10c. It could be observed that after the first cycle, the specific capacity decreased from 800 to $615 \mathrm{mAh} \mathrm{g}^{-1}$ and exhibited the same values even after the $50^{\text {th }}$ cycle, which denotes the high cyclic reversibility after the second cycle. Not really significant changes in the reversible capacity after $1-50$ cycles were visible at the voltage lower than $1.0 \mathrm{~V}$.

Figure 10d shows the potential voltages of the GNPs at the current density equal to $10 \mathrm{~mA} \mathrm{~g}^{-1}$ after the $1 \mathrm{st}, 2 \mathrm{nd}$ and 50th cycle. In order to maintain the readability of the presented graph, only the charging curves for the 2 nd and 50th cycle were included. It could be easily seen that even after the 2nd cycle, the specific capacity continually decreased, which makes the GNPs really unstable as the anode active material for LIBs, because in the case of the CSC (Fig. 10c) after the 2nd cycle, the capacity trend was visibly stable. Therefore, the significant irreversibility is visible during the charge/discharge process and the downward trend in capacity is maintained, which is characteristic of the graphene nanoplatelets and is confirmed by the $\mathrm{CV}$ test (Fig. 7). Therefore, they are rarely used in LIBs due to the high irreversibility of the potential profiles at the relatively low current densities. Thus, the GNPs could not be used in more demanding applications at higher current densities. However, due to the almost imperceptible changes in the capacity after the 2 nd cycle in the case of the CSC, it turns out to be a stable anode material that can be used in the lithium-ion cells. Additionally, the GNPs exhibit a smaller current efficiency after the cycles $(86 \%, 78 \%$ for the 5GNPs and the 25GNPs, respectively) than the trend CSs (even 99\% efficiency), which confirms a high irreversibility of the charge-discharge cycles.

Moreover, it should be noted, that the potential profiles (Fig. 10c, d) are truly similar to one another in their shape, which makes their structure truly related, but the CSC appears to be a more stable anode material compared to both GNPs.

In general, the 5GNPs show higher capacities than the 25GNPs, but also a truly comparable irreversibility of the charge-discharge process.

The demand for food is increasing; hence electrodes made from waste biomass represent attractive opportunities. Unfortunately, such batteries rarely maintain performance comparable to current state-of-the-art technologies. For example, an anode synthesized from avocado leftovers provides high cyclic stability (provides comparable capacity to graphite: $315 \mathrm{mAh} \mathrm{g}^{-1}$ at a current density of $100 \mathrm{~mA}$ $\mathrm{g}^{-1}$ ) [51-53].

Table 3 shows the literature data regarding the capacity and cyclic stability of the graphene-based materials applicable in LIBs.

According to Table 3 , the highest specific capacity exhibits the oxidized GNS, but the largest cyclic stability may be observed for the graphene nanocables/MoS ${ }_{2}$ hybrid. Moreover, pure graphene reaches high capacities up to $1116 \mathrm{mAh}$
Table 3 Various graphenebased materials as the anode material in LIBs

\begin{tabular}{|c|c|c|c|}
\hline Materials & $\begin{array}{l}\text { Specific Capacity } \\
\left(\mathrm{mAh} \mathrm{g}^{-1}\right)\end{array}$ & Cyclic stability & References \\
\hline GNS & 540 & 300 after $30 \mathrm{C}\left(50 \mathrm{~mA} \mathrm{~g}^{-1}\right)$ & {$[54-56]$} \\
\hline GNS & 1264 & 848 after $40 \mathrm{C}\left(100 \mathrm{~mA} \mathrm{~g}^{-1}\right)$ & {$[54,57]$} \\
\hline GNS & 1233 & 502 after $30 \mathrm{C}\left(0.2 \mathrm{~mA} \mathrm{~cm}^{-2}\right)$ & {$[54,58]$} \\
\hline $\mathrm{GNS} / \mathrm{Fe}_{3} \mathrm{O}_{4}$ & 1026 & 580 after $100 \mathrm{C}\left(700 \mathrm{~mA} \mathrm{~g}^{-1}\right)$ & {$[54,58]$} \\
\hline $\mathrm{GNS} / \mathrm{SnO}_{2}$ & 860 & 570 after $30 \mathrm{C}\left(50 \mathrm{~mA} \mathrm{~g}^{-1}\right)$ & {$[54,55]$} \\
\hline $\mathrm{GNS} \mathrm{C}_{60}$ (spacer molecules) & 784 & Not tested & {$[54,56]$} \\
\hline GNS/CNT (spacer molecules) & 730 & Not tested & {$[54,56]$} \\
\hline Graphite & 372 & 240 after $30 \mathrm{C}\left(50 \mathrm{~mA} \mathrm{~g}^{-1}\right)$ & {$[54-56]$} \\
\hline Ox-GNS & 1400 & In a range of 800 & {$[54,59]$} \\
\hline Graphene nanocables/MoS $\mathrm{Mo}_{2}$ & 1150 & 1150 after $160 \mathrm{C}\left(500 \mathrm{~mA} \mathrm{~g}^{-1}\right)$ & {$[60,61]$} \\
\hline $\mathrm{GNS} / \mathrm{Li}_{3} \mathrm{VO}_{4}$ & 220 & 220 after $500 \mathrm{C}\left(4000 \mathrm{~mA} \mathrm{~g}^{-1}\right)$ & {$[60]$} \\
\hline $\mathrm{CSC}$ & 790 & 615 after $50 \mathrm{C}\left(10 \mathrm{~mA} \mathrm{~g}^{-1}\right)$ & This work \\
\hline 5GNPS & 690 & 580 after $50 \mathrm{C}\left(10 \mathrm{~mA} \mathrm{~g}^{-1}\right)$ & This work \\
\hline 25GNPS & 620 & 565 After $50 \mathrm{C}\left(10 \mathrm{~mA} \mathrm{~g}^{-1}\right)$ & This work \\
\hline
\end{tabular}

GNS graphene nanosheet, $C_{60}$ carbon $\mathrm{C} 60, C N T$ carbon nanotube, $O x$ oxidized, $C$ cycle number 
$\mathrm{g}^{-1}$ and those values are almost the same for the CNT. Thus, it should be noted, that the more developed surface area enables higher capacities [62].

It is well known that carbon materials are of great interest in space, military equipment, sports equipment and electrochemical devices for energy storage and conversion. The advantages include the already mentioned low weight, developed specific surface and excellent thermal/electrical parameters [63-68].

Specific capacities obtained for the CSC (Fig. 10a) at $50 \mathrm{~mA} \mathrm{~g}^{-1}$ after the cycles are higher than for the GNS (all modifications and pure) (Table 3) and few-layer graphene (max. $368 \mathrm{mAh} \mathrm{g}^{-1}$ at $35 \mathrm{~mA} \mathrm{~g}^{-1}$ ) and the materials are much more stable after the cycles [51]. Table 3 also contains the results obtained for the electrochemical systems used in this work. We have observed much better results for carbon derived from starch than for the GNS or the GNS/ $\mathrm{SnO}_{2}$ (cyclic stability for starch $616 \mathrm{~mA} \mathrm{~g}^{-1}$ ). According to Fig. 10a, the capacity delivered an excellent coulombic efficiency of even $99 \%$. The capacity retention of the cells is an important parameter and a high-performance cell not only needs to keep an excellent long cycling stability but also needs to have an excellent coulombic efficiency. Before the carbonization process, which was the subject of our recent work [69], where raw starches were used as the active anode materials, the specific discharge capacities of the half-cells were equal to $418,385,360,266 \mathrm{mAh} \mathrm{g}^{-1}$ at the current density $50 \mathrm{~mA} \mathrm{~g}^{-1}$ after the first cycle for WS, CS, RS, PS, respectively. Therefore, in the following manuscript, the thermal modification significantly increased the capacity of the half-cells, making them more appropriate for industrial applications.

We all know very well that nature offers various types of biomass sources that are becoming more and more popular for the production of cheap and efficient energy storage devices. It has become very popular in recent years [70-74].

\section{Conclusions}

The development of the lithium-ion cells heavily depended on the optimization of the anode material. The use of the carbon materials initiated a new stage in the development of these systems. Carbon materials show different electrochemical properties depending on their crystal structure. Two types of carbon materials are used in the commercial lithium-ion cells. The first group are natural graphite materials with a highly ordered structure, while the second group are synthetically obtained graphites with an ordered structure, referred to as highly ordered pyrolytic graphites.

In summary, the physicochemical properties such as the well-developed specific surface area (over 300 times greater than before the thermal treatment and 3-4 times greater than for the GNPs) indicate very good sorption properties. Moreover, the cyclic stability has been improved compared to materials before modification, which is confirmed by the $\mathrm{CV}$ test and the low resistance. The main mechanism during charging is the diffusion of the lithium ions. It was confirmed by the good lithium ion diffusion coefficient values. In addition, the cell charge-discharge tests indicate high capacities that maintain stable values and small energy losses even when the current density changes. This material may find application in electrochemical capacitors, particularly the PSC and the 25GNPs, because of the irreversibility of the redox reactions.

The CSC presented the highest specific capacities (up to $1000 \mathrm{mAh} \mathrm{g}^{-1}$ ) at the current density $1 \mathrm{~mA} \mathrm{~g}^{-1}$. Therefore, the CSC is expected to be a better alternative as an anode carbon material for LIBs compared to the GNPs due to its high coulombic efficiency, stability during the chargingdischarging process, the cyclic reversibility during the tests and a higher specific capacity than many other anode carbon materials commonly used (e.g. graphite, GNPs, GNS).

Moreover, the as-obtained carbon structures (SCs) appear to have fewer structural defects than the GNPs, so the SCs demonstrate a small energy loss during the charge-discharge process compared to the graphene nanoplatelets, which makes them more electrochemically stable after the cycles.

Thus, the obtained SCs could be the next generation of graphene-based devices that may emerge as the non-toxic, renewable, cheap, novel and environmentally friendly carbon material for lithium-ion cells prepared without any use of chemical modifications.

Supplementary Information The online version contains supplementary material available at https://doi.org/10.1007/s12649-021-01465-3.

Acknowledgements This work was supported by the Polish Ministry of Science and Higher Education, Grant 0911/SBAD/2102.

Open Access This article is licensed under a Creative Commons Attribution 4.0 International License, which permits use, sharing, adaptation, distribution and reproduction in any medium or format, as long as you give appropriate credit to the original author(s) and the source, provide a link to the Creative Commons licence, and indicate if changes were made. The images or other third party material in this article are included in the article's Creative Commons licence, unless indicated otherwise in a credit line to the material. If material is not included in the article's Creative Commons licence and your intended use is not permitted by statutory regulation or exceeds the permitted use, you will need to obtain permission directly from the copyright holder. To view a copy of this licence, visit http://creativecommons.org/licenses/by/4.0/.

\section{References}

1. Salamia, M., Louis, H., Zafar, S.-U., Amusan, O.O., Magu, T.O., Hamzat, A.T., Pigweh, A.I., Akakuru, O.U., Adeleye, A.T., Ita, B.I.: Asian J. Nanosci. Mater. 2(1), 1 (2018) 
2. Roselin, L.S., Juang, R.-S., Hsieh, C.-T., Sagadevan, S., Umar, A., Selvin, R., Hegazy, H.H.: Materials 12(8), 1229 (2019)

3. Santner, H.J., Möller, K.C., Kohs, W., Veit, C., Lanzer, E., Trifonova, A., Wagner, M.R., Raimann, P., Korepp, C., Besenhard, J.O., Winter, M.: Supercapacitors, Chapters Carbon Anodes for Lithium-Ion Batteries and Carbonaceous Materials for Batteries, p. 157. Springer, New York (2006)

4. Yao, F., Pham, D.T., Lee, Y.H.: Chemsuschem 8, 2284 (2015)

5. Quiao, W., Yoon, S.-H., Mochida, I.: Energy Fuels 20, 1680 (2006)

6. Yuyama, K., Masuda, G., Yoshida, H., Sato, T.: J. Power Sour. 162, 1401 (2006)

7. Chmiola, J., Yushin, G., Gogotsi, Y., Portet, C., Simon, P., Taberna, P.L.: Science 313, 1760 (2006)

8. Fernández, J.A., Arulepp, M., Leis, J., Stoeckli, F., Centeno, T.A.: Electrochim. Acta 53, 7111 (2008)

9. Lewandowski, A., Olejniczak, A.: J. Power Sour. 172, 487 (2007)

10. Sheveleva, I.V., Zemskova, L.A., Zheleznov, S.V., Voit, A., Barinov, N.N., Sukhoverstov, S.V., Sergienko, V.I.: Russ. J. Appl. Chem. 80, 924 (2007)

11. Merino, C., Soto, P., Vilaplana-Ortego, E., Gomez de Salazar, J.M., Pico, F., Rojo, J.M.: Carbon 43, 551 (2005)

12. Yoon, S.-H., Lim, S., Song, Y., Ota, Y., Qiao, W., Tanaka, A., Mochida, I.: Carbon 42, 1723 (2004)

13. Portet, C., Yushin, G., Gogotsi, Y.: Carbon 45, 2511 (2007)

14. Yoon, B.-J., Jeong, S.-H., Lee, K.-H., Kim, H.S., Park, Ch.G., Han, J.H.: Chem. Phys. Lett. 388, 170 (2004)

15. Du, C., Yeh, J., Pan, N.: Nanotechnology 16, 350 (2005)

16. Yuan, D., Chen, J., Zheng, J., Tan, S.: Electrochem. Commun. 10, 1067 (2008)

17. Lewandowski, A., Galinski, M.: J. Power Sour. 173, 822 (2007)

18. Jerónimo, G.F., Mendoza, J.S., San Claudio, P.C.M., Terán, A.T., et al.: Waste Biomass Valoriz. (2021). https://doi.org/10.1007/ s12649-021-01377-2

19. Luchiari, I.C., Cedeno, F.R.P., Farias, T.A.M., Picheli, F.P., et al.: Waste Biomass Valoriz. (2021). https://doi.org/10.1007/ s12649-021-01379-0

20. Casagrande, M., Zanela, J., Wagner Júnior, A., Yamashita, F., et al.: Waste Biomass Valoriz. 2020(12), 3452 (2018)

21. Salimi, E., Saragas, K., Taheri, M.E., Novakovic, J., Barampouti, E.M., et al.: Waste Biomass Valoriz. 10, 3753 (2019)

22. Mei, G., Kumar, H., Huang, H., Cai, W., Gangadhara Reddy, N., et al.: Waste Biomass Valoriz. 12, 1493 (2021)

23. Gao, Y., Shi, W., Wang, W., Wang, Y., et al.: Ind. Eng. Chem. Res. 53(7), 2839 (2014)

24. Zhao, M., Li, B., Cai, J.-X., Liu, C., McAdam, K.G., Zhang, K.: Fuel Process. Technol. 153, 43 (2016)

25. Saeedfar, K., Heng, L.Y., Ling, T.L., Rezayi, M.: Sensors 13(12), 16851 (2013)

26. Alawi, O.A., Sidik, N.A.C., Kazi, S.N., Najafi, G.: J. Therm. Anal. Calorim. 135, 1081 (2019)

27. Kuan, C.-F., Chiang, C.-L., Lin, S.-H., Huang, W.-G., Hsieh, W.-Y., Shen, M.-Y.: Polym. Polym. Compos. 26(1), 59 (2018)

28. Chieng, B.W., Ibrahim, N.A., Wan Yunus, W.M., Hussein, M.Z., Silverajah, V.S.: Mechanical properties. Int. J. Mol. Sci. 13(9), 10920 (2012)

29. Karamikamkar, S., Abidli, A., Behzadfar, E., Rezaei, S., Naguib, H.E., Park, C.B.: RSC Adv. 9(20), 11503 (2019)

30. Gong, J., Zhou, Z., Sumathy, K., Yang, H., Qiao, Q.: J. Appl. Phys. 119(13), 135501 (2016)

31. Bakierska, M., Chojnacka, A., Swiętosławski, M., et al.: Materials 10, 1336 (2017)

32. Zhang, J., Xu, T., Cong, Y., et al.: J. Mater. Sci. 54(1), 11 (2019)

33. He, L., Wang, H., Zhu, H., Gu, Y., et al.: Appl. Sci. 8, 1 (2018)

34. Lin, P.-C., Wu, J.-Y., Liu, W.-R.: Sci. Rep. 8(1), 1 (2018)

35. Chen, J., Han, J.: Results Phys. 15, 102803 (2019)
36. Tian, L.-L., Zhuang, Q., Li, J., et al.: Chin. Sci. Bull. 56(30), 3204 (2011)

37. Qin, L.-C., Wang, Z.L., Hui, Ch.: Electron Microscopy of Nanotubes, p. 207. Springer, New York (2003)

38. Li, J., Luo, S., Zhang, B., Lu, J., Liu, W., Zeng, Q., Wan, J., Han, X., Hu, Ch.: Nano Energy 79, 105410 (2021)

39. Zhu, M., Meng, W., Huang, Y., Huang, Y., Zhi, C.: ACS Appl. Mater. Interfaces 6, 18901-21891 (2014)

40. Chen, W., Rakhi, R.B., Wang, Q., Hedhili, M.N., Alshareef, H.N.: ACS Appl. Mater. Interfaces 24, 3130-3143 (2014)

41. Luo, S., Li, J., Lu, J., Tao, F., Wan, J., Zhang, B., Zhou, X., Hu, C.: Mater. Today Phys. 17, 100337 (2021)

42. Wang, Q., Luo, Y., Hou, R., Zaman, S., Qi, K., Liu, H., Park, H.S., Xia, B.Y.: Adv. Mater. 31, e1905744 (2019)

43. Roselin, L.S., Juang, R.-S., Hsieh, C.-T., Sagadevan, S., et al.: Materials 12, 1229 (2019)

44. Ramasubramanian, A., Yurkiv, V., Foroozan, T., Ragone, M., et al.: J. Phys. Chem. 123, 10237 (2019)

45. Xiao, P., Lv, T., Chen, X., Chang, Ch.: Sci. Rep. 7(1), 1 (2017)

46. Lewandowski, A., Biegun, M., Galiński, M., Świderska-Mocek, A.: J. Appl. Electrochem. 43(3), 1 (2012)

47. Galiński, M., Lewandowski, A., Stępniak, I.: Ionic liquids as electrolytes. Electrochim. Acta 51, 5567 (2006)

48. Nan, X., Liu, Ch., Zhang, Ch., Ma, W., et al.: J. Mater. Chem. A 4, 9789 (2016)

49. Pan, D., Wang, S., Zhao, B., Wu, M., Zhang, H., Wang, Y., Jiao, Z.: Chem. Mater. 21, 3136 (2009)

50. Zhao, J., Buldum, A., Han, J., Lu, J.P.: Phys. Rev. Lett. 85, 1706 (2000)

51. Luo, R.-P., Lyu, W.-Q., Wen, K.-C., He, W.-D.: J. Electr. Sci. Technol. 16(1), 57 (2018)

52. Du, X., Du, W., Wang, Z., Liu, K., Li, S.: Mater. Sci. Eng. A 711, 633 (2018)

53. Yokokura, T.J., Rodriguez, J.R., Pol, V.G.: ACS Omega 5(31), 19715 (2020)

54. Brownson, D.A.C., Banks, C.E.: The Handbook of Graphene Electrochemistry, Graphene Applications, p. 158. SpringerVerlag, London (2014)

55. Paek, S.-M., Yoo, E., Honma, I.: Nano Lett. 9, 72 (2009)

56. Yoo, E.J., Kim, J., Hosono, E., Zhou, H.-S., Kudo, T., et al.: Nano Lett. 8, 2277 (2008)

57. Lian, P., Zhu, X., Liang, S., Li, Z., Yang, W., Wang, H.: Electrochim. Acta 55, 3909 (2010)

58. Zhou, G., Wang, D.-W., Li, F., Zhang, L., Li, N., Wu, Z.-S., Wen, L., et al.: Chem. Mater. 22, 5306 (2010)

59. Bhardwaj, T., Antic, A., Pavan, B., Barone, V., Fahlman, B.D.: J. Am. Chem. Soc. 132, 12556 (2010)

60. Fang, R., Chen, K., Yin, L., Sun, Z., et al.: Adv. Mater. 31(9), 1 (2018)

61. Kong, D., He, H., Song, Q., Wang, B., et al.: Energy Environ. Sci. 7, 3320 (2014)

62. Yuan, W., Zhang, Y., Cheng, L., Wu, H., et al.: J. Mater. Chem. A 4, 1 (2016)

63. Cao, Q., Zhu, M., Chen, J., Song, Y., Li, Y.: ACS Appl. Mater. Interfaces 12, 1210 (2020)

64. García-Mateos, J.W., Berenguer, R., Valero-Romero, M.J., Rodríguez-Mirasol, J., Cordero, T.J.: Mater. Chem. A 6, 1219 (2018)

65. García-Mateos, F.J., Berenguer, R., Valero-Romero, M.J., Rodríguez-Mirasol, J., Cordero, T.: J. Mater. Chem. A 2, 1458 (2014)

66. Qu, G., Cheng, J., Li, X., Yuan, D., Chen, P., Chen, X., Wang, B., Peng, H.A.: Adv. Mater. 28, 3646 (2016)

67. Thunga, M., Chen, K., Grewell, D., Kessler, M.R.: Carbon 68, 159 (2014)

68. Ding, R., Wu, H., Thunga, M., Bowler, N., Kessler, M.R.: Carbon 100, 126 (2016) 
69. Pigłowska, M., Kurc, B., Kubiak, A.: Bioelectrochemistry 136, 107619 (2020)

70. Tao, L., Huang, Y., Yang, X., Zheng, Y., Liu, C., Di, M., Zheng, Z.: RSC Adv. 8, 7102 (2018)

71. Liao, H., Zhang, H., Hong, H., Li, Z., Qin, G., Zhu, H., Lin, Y.: J. Membr. Sci. 514, 332 (2016)

72. Wang, S.X., Yang, L., Stubbs, L.P., Li, X., He, C.: ACS Appl. Mater. Interfaces 5, 12275 (2013)

73. Liu, L., Yang, X., Lv, C., Zhu, A., Zhu, X., Guo, S., Chen, C., Yang, D.: ACS Appl. Mater. Interfaces 8, 7047 (2016)
74. Jain, A., Jayaraman, S., Ulaganathan, M., Balasubramanian, R., Aravindan, V., Srinivasan, M.P., Madhavi, S.: Electrochim. Acta 228, 131 (2017)

Publisher's Note Springer Nature remains neutral with regard to jurisdictional claims in published maps and institutional affiliations. 